This is the final peer-reviewed accepted manuscript of:

Capacci, S., Mazzocchi, M. and Shankar, B. (2018), Breaking Habits: The Effect of the French Vending Machine Ban on School Snacking and Sugar Intakes. J. Pol. Anal. Manage., 37: 88-111. Doi:10.1002/pam.22032

The final published version is available online at: $\underline{\text { https://doi- }}$ org.ezproxy.unibo.it/10.1002/pam.22032

Rights / License:

The terms and conditions for the reuse of this version of the manuscript are specified in the publishing policy. For all terms of use and more information see the publisher's website. 


\title{
Breaking Habits: The Effect of the French Vending Machine Ban on School Snacking and Sugar Intakes
}

Sara Capacci Mario Mazzocchi Bhavani Shankar

Published on Journal of Policy Analysis and Management, 37(1), 88-111 https://doi.org/10.1002/pam.22032

Pre-proof accepted version

\begin{abstract}
This paper estimates the effect of the 2005 vending machine ban in French secondary schools on nutrient intakes and on the frequency of morning snacking at school. Using data before and after the ban, and exploiting the discontinuity associated with the age-dependent exposure to the ban, we specify a difference-in-differences regression discontinuity design. Since the relationship between age-at-interview and school level is not precise, we introduce fuzziness in the model. We find that the ban has generated a 10-gram reduction in sugar intakes from morning snacks at school, and a significant reduction in the frequency of these morning snacks. However, we find no evidence that the intervention affects total daily intakes, and our results are suggestive of compensation effects.
\end{abstract}

\section{JEL classification: I18}

Keywords: Fuzzy Regression Discontinuity Design; Difference in Difference; Vending Machine Ban; Policy Evaluation 


\section{INTRODUCTION}

Snacking patterns, together with the associated excess sugar and fat intakes, are recognized as a leading cause of excess weight in children and adolescents (Larson \& Story, 2013). Recent evidence from the U.S. shows that snacks represent about 27 percent of daily calorie intake in children, with desserts and sugar-sweetened beverages (SSBs) being the largest contributors (Piernas \& Popkin, 2010). According to data from the 2013/2014 National Health and Nutrition Examination Survey, one in five U.S. children aged between 12 and 19 exceeded the Centers for Disease Control and Prevention cut-off point for childhood obesity, a figure which has almost doubled over the last 20 years (Ogden et al., 2016). Such a trend is common to most high income countries in the world, and estimates from the Global Burden of Disease project indicate that the prevalence of overweight and obese children and adolescents in high income countries has risen from 16 percent to 23 percent between 1980 and 2013 (Ng et al., 2014).

A variety of policy measures have been implemented in high income countries to address overnutrition and obesity in childhood, ranging from providing information about the health risks, enforcing bans on the marketing of unhealthy foods and drinks, and discouraging consumption through taxation. There is an open debate and a quest for evidence on the effectiveness of individual measures or the combined effect of multiple interventions. ${ }^{1}$

Schools are considered a key environment to counteract childhood obesity. In the U.S., about 40 percent of youth food energy is consumed at school, and obesity trends are consistent with the increase in the number of schools that provide access to "junk" food (Anderson \& Butcher, 2006). Since school meals are regulated and expected to meet healthy nutrition standards, experts blame the so-called "competitive foods" sold through vending machines (VMs) or snack bars. There is evidence that drinks and foods sold from VMs are on average higher in calories, sugars, and fats relative to the recommended intakes, both in the U.S. (Pasch 
et al., 2011) and Europe (Kocken et al., 2012). Thus, restrictions and bans on competitive foods are expected to improve children's diets (Story et al., 2009).

The relationship between access to VMs and unhealthy dietary behaviors is strong and significant in U.S. middle schools, although less evident in high schools (Rovner et al., 2011). Some U.S. states and school districts have restricted or banned the sale of SSBs in secondary schools (Mello et al., 2008), and the percentage of school children with access to SSBs from VMs in U.S. middle schools has dropped from 77 percent in 2006/2007 to 63 percent in 2010/2011, although it is still above 90 percent in high schools (Terry-McElrath et al., 2012).

Starting from the 2005/2006 school year, France has adopted a nation-wide regulation banning vending machines from all secondary schools, regardless of the items on sale, while primary schools had no VMs on their premises even before the ban. Our study aims at providing an ex-post evaluation of the effects of the VM ban on French school children's calorie and nutrient intakes, and morning snack frequencies. To the best of our knowledge, this is the first evaluation that specifically addresses the effects of a vending machine ban on nutrient intakes. The French nation-wide policy provides a valuable setting to assess the ban's dietary outcomes. More specifically, we test whether: (a) the ban is associated with a reduction of calories, sugar, and saturated fat intakes during morning school breaks; (b) the frequency of morning snacks at school is affected by the ban; (c) there are compensating behaviors due to the lack of prior satiation during other meal occasions at school or outside the school environment.

School VM bans are still very controversial, for a variety of reasons. First, VMs are a profitable operation, and school (district) finances can rely heavily on revenues from contracts with VM suppliers, which generally consist of lump sum cash advances to obtain multiannual exclusive rights and shares of sales revenues. The value of cash advances can reach $\$ 10$ million per district for a 10-year contract (Anderson \& Butcher, 2006), whereas the median revenues from soft drink sales are estimated at $\$ 500$ per year in middle schools and $\$ 6,000$ in high 
schools, which corresponds to a median revenue per student of $\$ 0.70$ and $\$ 6.48$, respectively (Johnston et al., 2007).

Second, their effectiveness is still disputed because of potential compensation effects (Taber et al., 2014), i.e., those children who cannot purchase their snacks or sodas from VMs because of the ban may still get them outside school, with no reduction of their daily intakes. Furthermore, a recent study allowing for the potential endogeneity of school environments has found no significant relationship between junk food availability in schools and children's body mass index (Datar \& Nicosia, 2012). Third, VMs may be a vehicle to promote consumption of healthy foods, and provision of fruit and vegetables in VMs has been shown to increase intakes (Kocken et al., 2012; Rovner et al., 2011).

Unfortunately, scientific evidence on the effects of school bans is scarce, and mostly confined to the impact on soft drink consumption among U.S. school children (Driessen et al., 2014). Bans affecting provision of soft drinks are the most frequent restriction in U.S. schools, and they are the focus of the few ex-post evaluations available in the literature (Cradock et al., 2011; Fletcher et al., 2010; Huang \& Kiesel, 2012; Taber et al., 2012, 2014).

Based on a nationally representative sample of 11,052 school children from U.S. middle schools in 2004 and 2007 Fletcher et al. (2010) compare soft drink intakes of students attending schools with access to VMs to those of their peers in schools that implement a VM ban. While consumption at school was significantly lower (but not zero) in the latter group, no significant difference was found in the overall weekly consumption, nor in the obesity or overweight index.

Taber et al. (2012) exploit the same data source and confirm the results in Fletcher et al. (2010) by including information on state-level school sale restrictions in their model. Taber et al. (2014) apply a similar model to a different nationally representative data source on 10,887 high-school students in 2010. Again, the overall soda consumption levels were not lower for 
those students living in states with school bans, and the evidence seems to suggest that compensation effects might even exceed the positive effects of the ban.

However, these compensating behaviors are not found in Huang and Kiesel (2012) in relation to the 2006 Connecticut ban on soft drink sales in schools. This study makes use of home scan data on household soft drink purchases, and adopts a (triple) difference-in-difference approach to compare households with and without children, before and after the ban, and using cities outside Connecticut as a natural control group.

A similar ban was introduced in Boston high schools in 2004, and Cradock et al. (2011) find a significant decline in self-reported SSB consumption among Boston teenagers, over a post-ban period that saw stable consumption at the national level, a result that would suggest no compensation effects.

The evidence on compensating behaviors from biological research is suggestive of heterogeneous responses, depending on gender, age group, the specific nutrient, and the type of product (e.g., liquid versus solid sugars). However, randomized control trials on children suggest that interventions aimed at reducing sugar intakes are not associated with significant BMI changes (Malik et al., 2013; Te Morenga et al., 2013), especially when the interventions were school-based. The physiological link between consumption of energy-dense foods and total energy intake across meal occasions has been explained by mechanisms of satiety and (cerebral) food rewards (Bellisle et al., 2012). VM bans act on the access to unhealthy snacks and drinks in the regulated environments, but the compensating behaviors induced by the above mechanisms hinder their effect on the overall diet. This suggests that an effective intervention should act on both dimensions to avoid compensation effects (Drewnowski \& Bellisle, 2007).

The French VM ban, combined with the availability of individual data from the French national nutrition surveys before and after the ban, provides an ideal opportunity to evaluate the nutritional effects of removing VM from secondary schools, without restricting the focus 
to soft drinks. As evaluation outcomes, we consider children's intakes of the most relevant nutrients, sugars, and saturated fats. Furthermore, the data-sets allow us to isolate intakes for each specific meal occasion and week day, indicating the exact date and time when a food is consumed. Thus, we focus on morning snacks during school-days, since they are guaranteed to be consumed on the school premises and are exposed to the ban, whereas lunch and afternoon snacks may happen outside school. We also explore the effects on morning snack frequency over the school week. By considering other meal occasions, at school and outside the school environment, we investigate compensation effects.

No information exists about the availability of VMs in schools, thus we adopt an identification strategy that relies on a fuzzy differenced regression discontinuity design (FDRDD), a combination of a fuzzy regression discontinuity design (RDD) with a difference-indifference model (DiD). Since kids in primary schools had no access to VMs before or after the national ban, they provide a natural control group for middle school students who had access to VMs before the ban and no access afterwards, which is the DiD part of our model.

Since the ban targets school children when they enter middle school, we use the age of entry at middle school as a cut-off point, and look at the impact around the threshold, which is the RDD part of our model. The fuzzy generalization of the RDD model is due to some uncertainty on the entry age for middle school. Our data provide information on age in years at the time of the interview, with interviews distributed along the school year, but not the date of birth. Since the legal age for entry to middle schools in France depends on birth year, which cannot be inferred exactly from our data, the relationship between our age measure and the school level is probabilistic. The possibility of grade repetition and early entrance adds further uncertainty.

Our results indicate a significant decrease in snack frequencies and a reduction of sugar intakes during the morning snacks. When considering the daily diet, we find no change in total 
sugar intakes. These findings are robust to changes in the model assumptions, such as the choice of different bandwidths, the inclusion of individual covariates, the extension to consider afternoon snacks, the non-parametric specification of outcome-age relationship.

When considering all meals except the morning snack we find a significant increase in sugar intakes, which is suggestive of compensation effects. Research in clinical nutrition associates sweetness with a short-term satiation effect, even when the energy intake is low (Anderson \& Woodend, 2003), and this could explain why reduction of school sugar intakes — hence lack of satiation-is compensated in subsequent meals. Our findings have relevant policy implications, as reducing sugar intakes or decreasing the number of meal occasions in school children may not generate the desired effect, if measures like a VM ban are not part of a broader multi-level policy which mitigates the compensation effects, addressing not only the availability dimension but also the physiological (satiety) and behavioral (food reward) dimensions.

The remainder of this paper is organized as follows. In the next section, we describe the background of the 2005 French policy and the data-sets, and in the Methodology section we present the empirical evaluation strategy and the related econometric issues. The following section reports the results together with a variety of robustness checks, and discussion and conclusions are provided in the concluding section. 


\section{POLICY BACKGROUND AND DATA}

\section{Policy}

French nutrition policy is guided by the National Nutrition and Health Program (PNNS), first implemented over the period 2001 to 2005, then updated regularly every five years (Chauliac \& Hercberg, 2012; Hercberg et al., 2008;). The PNNS sets a number of nutritional objectives both for the population at large, and for specific sub-groups. Within the first PNNS, several actions were directed at the school environment. Beyond recommendations to improve the nutritional quality of lunches taken at school — an option chosen by about 60 percent of school children - the 2004 Public Health Law ${ }^{2}$ provided for the banning of VMs in all schools (Chauliac \& Hercberg, 2012). The measure was enforced at the start of the 2005/2006 school year (September 2005).

French school children typically start their school day with breakfast at home ${ }^{3}$ and enter school at about $8 \mathrm{am}$. At mid-morning, primary school children can be provided a snack by the school, or they may be allowed to bring it from home, with a large heterogeneity across schools. Middle school children have a 15 minutes mid-morning break, which allows them to eat a snack brought from home, purchase food and drinks in school bars, or-prior to the ban-from vending machines, without leaving the school premises. In high schools, breaks are determined by individual school schedules, and there may be longer breaks, where children may consume foods brought from home, buy competitive foods at school, or in some cases they may even leave the school premises and buy food outside. At all school levels, the lunch break is quite long, between 1.5 and 2.5 hours, and school children may consume lunch at the school canteen, purchase foods, or leave school and eat lunch outside.

The 2005 VM ban has eliminated one — but not all—of the sources of competitive foods in secondary schools. Among the evidence that underpinned the decision of the French 
government to ban vending machines, was an evaluation of the mid-morning snack at school ${ }^{4}$ provided by the French Food Safety Authority (AFSSA) in 2003. The AFFSA position on morning snacks was centered on their contribution to excessive calorie intakes, which also noted that their composition, timing, and undifferentiated characteristics make them ineffective in addressing insufficient intakes for the minority of children not taking breakfast at home. A similar statement was produced by the French Pediatric Nutrition Society (Bocquet et al., 2003), which explicitly mentions the poor nutritional quality of the morning snacks taken at school, characterized by an excess of sugars and saturated fats.

Other forms of food supply, such as those organized by the student associations in high schools or direct sales, have survived the national regulation and were not restricted. ${ }^{5}$ In 2007 , the Ministry of Education revised the guidelines on school lunch for all school levels, mainly by providing recommendations on the frequency of consumption by food group. These guidelines have not been effective in improving the overall school food provision, to the point that the French government acknowledged the lack of compliance and introduced a new law on school meals in 2010, which came into force from the 2012 school year onward (Dubuisson et al., 2015).

\section{Data}

We use data from two waves of the French National Nutrition Survey (Enquête Individuelle et Nationale des Consommations Alimentaires) conducted by the French Food Safety Agency in 1998/1999 (INCA1) and 2006/2007 (INCA2). The timing of the INCA2 survey allows us to consider the VM ban following its full implementation, but precedes the introduction of other school-based measures such as the revisions of the school meal guidelines in September 2007 and the 2010 law that entered into force in September 2012.

The INCA1 sample consists of two independent sub-samples, composed of 1985 
adolescents and adults (aged 15 years and over) and of 1016 children (aged 3 to 14 years), respectively. Similarly, the INCA2 sample includes two independent samples of 1455 children and adolescents aged 3 to 17 and 2624 adults aged 18 to 79 . These samples are designed to be representative of the French population, and the sampling procedure is described in detail in Dubuisson et al. (2010) and in Lioret et al. (2009, 2010).

Both the INCA1 and the INCA2 survey assess dietary intake using a seven-day food diary. The data include information on the quantity of food consumed (classified into more than 1300 food types), the associated nutrient intake (computed based on the French Food Composition Table produced by AFFSA), the eating occasion (breakfast, lunch, dinner, and between-meals snacks) and the date of each meal. The translation of food intakes into nutrients is based on food composition tables provided with each of the INCA surveys. These tables are produced by the French Information Center on Food Quality (Ciqual) and report the nutrient contents of 1093 items in INCA1 and 1342 items in INCA2. All values are given as "per 100 grams edible portion," i.e., meat without bone, apple without core, etc. For the purpose of our study, we compute individual nutrient intakes for each meal occasion by multiplying the quantity of each specific food item as reported in the food diary by its nutrient content. We consider child energy intakes (in Kcal), and intakes for (saturated) fats and sugars. ${ }^{6}$

Given our focus on a school-based policy, we restrict the sample to school day records. Accounting for regional differences in official school holidays we discard holiday periods. At the time of the two surveys, the French school week could vary across schools and could be either on four or five days including, or not, Wednesdays or Saturdays, depending on the school policy. To avoid inconsistency between schools we exclude Sunday, Wednesday, and Saturday records from our sample. A further aspect to be considered is the timing of between-meals snacks. Those taken between breakfast and lunch are necessarily consumed at school, whereas afternoon snacks may be taken before or after leaving school, and our data do not provide 
explicit information about the location where the snack is taken. Thus, our target sample includes individuals aged between 6 and 18 whose intakes are observed for at least one school day during the food diary period. The resulting potential sample size is 1517 , with 543 observations from INCA1 and 974 from INCA2. The actual estimation samples depend on the definition of the outcome measures.

Intake measures for single meal occasions are conditional on individuals reporting nonzero calories for such meal occasions. Considering the morning break, this restricts the sample to 484 observations. Instead, the snack frequency is defined as the ratio between the number of valid school-day morning snacks (non-zero calories) and the number of school-day records for each student, where the latter can vary between one and four due to holidays. Thus, the target sample is the overall one (1517), where each child has a frequency value between 0 (no morning snacks) and 1 (morning snack taken in each of the available school days).

\section{METHODOLOGY}

\section{Identification Strategy}

According to the policy setting, the student's school level determines her exposure to the ban. Since school levels depend on age, we use age as the assignment variable for the intervention. ${ }^{7}$ The discontinuity of the exposure function around a specific age cut-off allows identification of the ban effect through a RDD. Under the RDD approach, when the (potential) outcome is a continuous function of the assignment variable at the cut-off, any difference in the observed outcome of exposed and non-exposed subjects around the cut-off can be ascribed to the intervention. $^{8}$

In our data-set, the relationship between age and school level is not strictly deterministic for two reasons. A first source of noise comes from the definition of our age variable. In the 
INCA surveys age is measured as age in years at the time of interview, whereas it is the birth year that determines the legal age for access to secondary school (11 years old in France). The birth year cannot be exactly inferred from our age variable and the date of interview. For example, students born in 1994 enter the first year of secondary school during the school year 2005/2006. However, for a student whose age in years is 11 and who was interviewed in March 2006, it is impossible to establish whether her birth year is 1995 (e.g., she was born in January 1995) or 1994 (e.g., she was born in December 1994). A second source of noise is the possibility that students have been delayed by grade repetition ${ }^{9}$ or have entered school a year early. Thus, considering age in years at the time of the interview, the probability of attending secondary school increases by less than one at age 11 .

The choice of the cut-off point is driven by information available in the INCA2 survey, where the school level attended is provided. The proportion of students aged below 11 who already attend a secondary school is fairly low, about 3 percent for those aged 9 and 4 percent for those aged 10. This percentage rises to 50 percent when the age at interview is 11 and to 91.3 percent when it is 12 . At 13 , all children in the INCA2 sample were in a secondary school. Based on these figures, ages 11 and 12 are both potential discontinuity points. We take 12 as the baseline discontinuity point, ${ }^{10}$ and-as discussed later-we consider 11 as an alternative cut-off point in our validation checks.

Hence, based on a fuzzy RDD specification and following Hahn et al. (2001), we estimate the ban impact using a two-stage least squares (TSLS) regression. In the first stage we estimate the jump in the probability of attending secondary school at the cut-off using the following equation:

$$
W_{i}=\delta_{0}+\delta_{1} I\left(X_{i}>x_{0}\right)+\delta_{2}\left(X_{i}-x_{0}\right)+u_{i}
$$

where $W_{i}$ is the probability of attending secondary school for individual $i, X_{i}$ denotes her age, $x_{0}$ is the cut-off point determining discontinuity in the probability of secondary school 
attendance, $I\left(X_{i}>x_{0}\right)$ is the binary indicator that acts as the excluded instrument, taking on the value of 1 when $X_{i}$ exceeds the cut-off, and $u_{i}$ is a stochastic error term. In the second stage, we estimate the outcome equation:

$$
Y_{i}=\alpha+\beta\left(X_{i}-x_{0}\right)+\tau \widehat{W}_{i}+\gamma I\left(X_{i}>x_{0}\right)\left(X_{i}-x_{0}\right)+v_{i}
$$

where $Y_{i}$ denotes the outcome for individual $i, \widehat{W}_{i}$ is the predicted probability from the first stage, $v_{i}$ is a stochastic error term, and $\tau$ provides an estimate of the (local) average causal effect of the ban on the sub-population above the cut-off. As per Lee and Lemieux (2010), the interaction term $I\left(X_{i}>x_{0}\right)\left(X_{i}-x_{0}\right)$ allows the slope of the regression to differ on either side of the cut-off, i.e., the model incorporates a piecewise linear spline with a kink at the cut-off point.

Correct identification of the ban effect would require that the policy is the only factor affecting the continuity of the outcome function around the threshold. More realistically, several behavioral and environmental changes relevant to food choice occur when children move from primary to secondary school (e.g., change in meal timings, level of financial independence from parents, etc.), which undermines the RDD assumption of local continuity of the outcome functions around the cut-off.

We address this potential threat by considering pre-policy data as in a difference-indifferences setting. What we require to be continuous around the cut-off is not the outcome function in levels, but the pre-post difference in the outcome functions in absence of treatment. If any discontinuity arises, this can be ascribed to the intervention. Under this combination of the DiD and RDD approaches, the effect of the ban is correctly identified provided the common trend assumption holds, at least at the discontinuity point. This implies that those effects of the transition to secondary school that are unrelated to the policy have not changed between the two periods. Thus, we combine the fuzzy RDD models before and after the policy within a DiD setting. After pooling the two data-sets, before and after the VM ban, we define a pre-post 
dummy $D i$ that takes a value of 1 when the subject $i$ is observed after 2005 and 0 otherwise. Within a fuzzy setting, the second stage equation becomes the following difference-indifference regression discontinuity model (fuzzy DD-RDD):

$$
\begin{aligned}
Y_{i} & =\alpha_{0}+\beta_{0}\left(X_{i}-x_{0}\right)+\tau_{0} \widehat{W}_{i}+\gamma_{0} I\left(X_{i}>x_{0}\right)\left(X_{i}-x_{0}\right)+\tau_{1} D_{i} \\
& +\tau_{2} D_{i} I\left(X_{i}>x_{0}\right)+\gamma_{1} D_{i}\left(X_{i}-x_{0}\right)+\gamma_{2} D_{i} I\left(X_{i}>x_{0}\right)\left(X_{i}-x_{0}\right)+\varepsilon_{i}
\end{aligned}
$$

where $\tau_{2}$ provides a local estimate of the effect of the ban on school children at age $x_{0}$. The inclusion of the interaction terms allows for different slopes before and after the ban, and between students below and above the cut-off age. Given our identification strategy, a ban that is effective in reducing unhealthy intakes or snacking frequencies would lead to a negative and significant coefficient $\tau_{2}$.

\section{Estimation Strategies and Bandwidth Selection}

The fuzzy DD-RDD model (3) nests two local linear regressions (LLR) over a selected window of observations around the cut-off point, before and after the policy. Estimation-wise, there is no difference compared to the standard one-period RDD model discussed in Hahn et al. (2001) and Imbens and Lemieux (2008). From a non-parametric perspective, this corresponds to adopting a rectangular kernel specification over the full sample, where weights 1 or 0 are attributed to the observations depending on whether they belong to the selected window or not. The bandwidth, which is the range of values of the assignment variable to be considered for estimating the LLR, is crucial in RDDs. The linear approximation is more likely to hold within small bandwidths, while it may generate biases over large bandwidths when the underlying function is not linear. Thus, there is a trade-off between the precision of estimates that increases with the number of selected observations and these potential biases due to the linear approximation.

We adopt a standard cross-validation approach to select the optimal bandwidth, based on 
the "leave-one-out" procedure proposed by Ludwig and Miller (2007) and Imbens and Lemieux (2008) for the RDD context. The data-driven algorithm detects the bandwidth that guarantees the best fit of the linear model to the data. For each potential bandwidth $h$, a mean square error is obtained through the following steps: (1) considering only observations to the left of the cutoff point $x 0$, the outcome variable $Y i$ is regressed on the assignment variable $X_{i}$ on the subsample $X_{i} \in\left[x_{0}-1-h ; x_{0}-1[\right.$; (2) use the estimated model to obtain the out-of-sample prediction of $Y_{i}$ for $X_{i}=x_{0}-1$; (3) move one step to the left and estimate the regression on the sample $X_{i} \in\left[x_{0}-2-h ; x_{0}-2\right.$ [ to generate out-of-sample predictions of $Y_{i}$ for $X_{i}=x_{0}-$ 2 ; (4) repeat step 3 for all remaining observations to the left of the cut-off point, until sufficient observations are available; (5) apply a mirror procedure to the right side of $x 0$ to obtain predictions; (6) use the predicted values $\widehat{Y}_{l}$ to calculate the bandwidth-specific mean square error, $\operatorname{MSE}(h)=\sum_{i \in S}\left(Y_{i}-\hat{Y}_{i}\right)^{2} / N_{S}$ where $S$ is the sub-set of observations for which it has been possible to obtain predictions and NS is the number of observations in $S$. The smallest $M$ $S E$ identifies the optimal bandwidth.

Based on the LLR specification, we estimate both the first stage (treatment) and second stage (outcome) regressions using the same bandwidth, as recommended by Lee and Lemieux (2010). The first stage equation can be estimated either as a logit model or using ordinary least squares as per Lee and Lemieux (2010). The coefficients of the first stage equation are estimated using INCA2 data only, as information on school level is unavailable for INCA1. We make the reasonable assumption that the probability of being at secondary school conditional on age does not vary across the two surveys. We estimate the second stage equation by ordinary least squares (OLS).

\section{Validation of Results}

Since results depend on a number of elements related to model specification and a variety of 
assumptions on the identification of the policy effect, we run a number of robustness checks and validation tests.

In terms of model specification, our approach assumes that the relationship between the outcomes of interest and the assignment variable is locally linear. We check the sensitivity of our results to the linearity assumption by comparing impact estimates across all potential bandwidths relative to the optimal one. As a further validation approach, we estimate the model on the full sample of observations through a kernel-weighted local polynomial regression (KLPR), using a Gaussian kernel for weighting (Fan \& Gijbels, 1996). When LLR estimates based on the optimal bandwidth are consistent with those based on the other potential LLR bandwidths and on the KLPR model, then we can safely conclude that they are robust to the local linearity assumption.

A second validation check relates to the inclusion of covariates in the fuzzy differenced RDD. The model follows a difference-in-difference specification, and since our data-set consists of two repeated cross-sections, we may want to control for changes in the sample composition before and after the policy implementation. To this purpose, we re-estimate the models including a set of covariates on the right-hand side of the LLR equation, a standard check suggested in Lee and Lemieux (2010). The available covariates are gender, weight, height, and household size, and we expect that controlling for these variables does not affect the size and significance of the estimated impacts.

Finally, our model specification allows for fuzziness in the assignment rule, but it is useful to compare our results to the more restrictive assumption of a sharp assignment. This comparison assesses the extent to which our results depend on the fuzzy specification.

A second battery of validity checks refers to the assumptions behind the identification of the policy effect relative to the various meal occasions. Our baseline outcome measures refer to the mid-morning snack, that is the meal occasion most likely to be affected by the removal 
of VMs. The key consideration behind this assumption is that this meal occasion is guaranteed to occur at school, whereas children have the option to consume lunches and afternoon snacks outside school. For our validity checks to support the baseline identification strategy, no policy impact should emerge when the outcome measures record out-of-school consumption only. Similarly, when the outcome measures refer to both at-school and out-of-school meal occasions, the estimated impact should be lower (or at most equal) relative to the impact estimated on the mid-morning break only.

We extend the outcome measures and the estimation sample to the following meal occasions during school days: (a) both morning and afternoon snacks; (b) afternoon snacks only; (c) lunch; (d) dinner; and, (e) all meal occasions throughout the day. When our baseline model detects a significant impact of the VM ban, support for our identification strategy requires an effect of the same (negative) sign to emerge from (a) and (b), but lower in absolute terms relative to the baseline estimates. When considering school-day lunches (c), not only do children have an out-of-school option, but intakes are also likely to depend on the overall canteen offer rather than the availability of VMs. In this case, no policy effect should emerge, otherwise we could not rule out that the baseline estimates capture broader trends in the school food environment or in children's habits. Dinner on school days (d) goes one step further, as this meal occasion is guaranteed to occur out-of-school. Any significant reduction in intakes could be interpreted as a falsification of the identification strategy, since there is no immediate reason for the ban to affect dinner intakes.

The overall daily intake (e) can be interpreted as a measure of the effect of the policy on the daily diet of children. Our sample is extended to include those children who do not consume snacks at school and considers all out-of-school meals. Provided that no concurrent policy acts on children entering secondary schools, the resulting effect should be equal or smaller in absolute terms relative to the baseline estimate. A larger impact could imply that the baseline 
model captures broader changes than those induced by the policy of interest, whereas a null impact might suggest that the scope of the ban is too limited to induce relevant modifications in diets, because of compensation effects or the narrow targeting of a policy affecting VM users only.

A final set of validity checks refers to our choice of the cut-off point at the age of 12 . As discussed, the obvious alternative would be to choose 11 as the cut-off, as roughly 50 percent of the children enter secondary schools at this age. Given that our fuzzy approach is designed to control for the uncertainties in the assignment rule, changing the cut-off point to another acceptable value should return similar estimates of the policy impact. On the other hand, no relevant policy-related discontinuity occurs at ages above 12 , when all the children in our sample are in secondary school. Thus, we estimate our model with a set of placebo discontinuity points above 12. Validation of our baseline model requires that no significant policy effect should emerge.

\section{RESULTS}

Morning snacks at school account for about 9 to 10 percent of children's total daily calorie intake. A comparison of data from the INCA1 survey and those from the INCA2 survey is provided in Table 1. Consistent with our policy identification strategy, we refer to primary school children when their age is below 12 and to secondary school children when they are aged 12 or above. On average, there is a general reduction in calorie and nutrient intakes between the two surveys, independent of the school level, and for both morning intakes at school and total daily intakes. Thus, the main context is one where children's diets tend to include less calories, sugars, and fats at all ages in INCA2 compared to INCA1.

Sugar consumed at school represents a major portion of the total daily amounts. According 
to the INCA1 survey, those children in primary and secondary schools taking the morning snack consumed in such meal occasions 14 percent and 19 percent of their total daily sugar intakes, respectively. Considering the INCA2 survey, the relative weight of morning snack intakes is smaller and the gap between school levels changes direction, with morning intakes dropping to 13 percent of total intakes of primary school children and to 11 percent for secondary school children.

[Table 1 approximately here]

The proportion of school mornings when a snack is consumed also varies between the two surveys, and between the two groups. In 1998/1999 (INCA1), the proportion of morning snacks consumed was 21 percent and 11 percent for primary and secondary school children, respectively. The INCA2 survey records an increase in this frequency for both groups, 26 percent and 16 percent, respectively. On balance, the data suggest that school children consume morning snacks more frequently, but their incidence on total intakes has become smaller, especially for sugar.

The French VM ban may have acted on morning snacking habits in two ways. First, by reducing the opportunities for morning snacks in secondary schools. Second, by reducing the overall school availability of foods and drinks rich in sugar and (saturated) fats.

We have information about the frequency of use of VMs only for the INCA2 survey, which was run after their removal from schools. We define vending machine users as those who purchase foods or drinks from a vending machine at least once a week. The proportion of VM users is an increasing function of the school level ${ }^{11}$ as only 16 percent of primary school children regularly buy foods or drinks from VMs, but the proportion rises to 28.5 percent for middle school children and to 41 percent for high school children. 
Table 2 shows that VM use is associated with a less healthy lifestyle. Soda consumption is more than twice as high for users, who also consume fast food meals more frequently, and spend more time in front of a PC or TV screen. On average, the level of calorie, sugar, and (saturated) fat intake is slightly higher for users, although this might be due to the fact that the proportion of VM users is substantially higher in secondary schools. However, if we consider secondary school children only, intakes are still higher for users. These figures suggest that a policy targeting VM users is well positioned, and they also indicate that some differences between users and non-users persist after the removal of VMs from schools.

[Table 2 approximately here]

\section{Impact on School Snacks}

In our analysis, we first focus on school snacks in the morning, as this is the only meal opportunity that is certain to take place at school, whereas lunches and afternoon snacks potentially can be consumed outside the school premises.

[Figure 1 approximately here]

Figure 1 displays the average outcomes by age at the interview before and after the ban, together with two separate quadratic fits below and above the cut-off age of 12, using the full sample of observations. Before the ban, the graphics are suggestive of discontinuities around the cut-off age for the morning snack frequencies and sugar intakes, whereas the jump is less evident for other intakes. After the ban, the discontinuities become negligible for the former outcomes, whereas no apparent change in the discontinuity emerges for the three other outcomes. 
[Table 3 approximately here]

Using the available information from the INCA2 survey, we estimate the first stage equation (1) by regressing the binary variable representing children's school level on age. ${ }^{12}$

Table 3 reports the impacts estimated through the second stage local linear regression (2) with 12 as the discontinuity point and using both INCA1 and INCA2 data. ${ }^{13}$ The optimal bandwidth varies by outcome variable, and the numbers in bold indicate the impact estimated on the optimal bandwidth for each outcome. In order to check for the sensitivity of our estimates to the bandwidth choice, the table also reports the estimates for the other bandwidths.

Considering the sub-sample of children taking the morning snack, the ban has significantly reduced sugar intakes by a quantity varying between 9.5 and 11.7 grams depending on the chosen bandwidth, with an estimate of about 10.5 grams for the optimal bandwidth (age 9 to 15). The morning snack frequency computed on the full sample also reacts significantly at the threshold. The model detects a reduction in the average calorie intake of those taking the morning break, but this is not significant. Similarly, no significant impact is detected for total fats and saturated fats.

The fact that changing the bandwidth and the number of observations does not generate major changes in the size effects and their significance levels for all outcomes is a first element suggestive of robustness. The reduction in sugar intakes without significant drops in other nutrients may suggest that the ban has been effective in reducing foods and drinks that are dense in sugars but not necessarily in fats, an obvious candidate being SSBs.

\section{Validation}

Estimates from the baseline model are consistent across different bandwidths, which is 
suggestive of robustness to the local linearity assumption. We explore the robustness of our impact estimates by running the other validation checks described earlier. Table 4 refers to the sensitivity of the estimates to different specification choices. The estimation of a Kernelweighted local polynomial regression using the full sample (Model 2 in the table) further confirms results from the baseline LLR model. The semi-parametric model returns significant impact estimate for sugars, only slightly smaller (around 9 grams versus 10.5 for the baseline model). The estimated impact on the morning snack frequency is almost identical and equally significant, while impact estimates for all other outcomes remain non-significant.

[Table 4 approximately here]

The inclusion of covariates on the right-hand side of the second stage FD- RDD equation (Model 3 in the table) also returns very similar estimates. Finally, estimates ignoring the uncertainty in the assignment rule and assuming a sharp discontinuity at the cut-off (Model 4 in the table) are slightly smaller than the baseline ones, but consistent in terms of direction and significance. Overall, our findings are robust to these different specification choices.

A second battery of tests relates to the assumptions behind the policy identification strategy and results are shown in Table 5. When we reshape the sample to include school children who consume non-zero calories in at least one of the two potential breaks (morning or afternoon) and consider the total intakes from both breaks as the outcome, once more we find results (Model 5 in the table) that are not dissimilar from the baseline estimates. The impact on sugar intakes is smaller, but more significant. The extension of the sample improves the efficiency of estimates, while the smaller impact is consistent with the noise due to the possibility that the afternoon break is consumed out of school. This interpretation is confirmed when the sample is confined to those school children who consume non-zero calories (Model 6 in the table) 
during the afternoon break. The signs of the estimated impacts are all negative, but their size is considerably smaller, to the point that no significant impact is detected. Lunch and dinner (Models 7 and 8 in the table) are meal occasions that we assume to be unaffected by the VM ban. Hence, the finding that all impacts are non-significant and close to zero can be seen as supportive of our policy identification strategy.

The last model in the table (Model 9) is expected to reflect the impact of the VM ban on the daily intakes on the overall student population, which also includes children who are not consuming snacks at school. In other words, it explores whether the scope of the policy is broad enough to induce changes in the overall diet of secondary school students. Thus, the nonsignificant impacts we find ${ }^{14}$ are subject to two potential interpretations: (1) targeting the use of vending machines does not suffice to alter the average diet of French secondary school children; (2) even when school behaviors are influenced by the policy, out-of-school meal situations may provide an opportunity for compensation. This latter hypothesis is explored in the next sub-section.

[Table 5 approximately here]

The final set of validation checks refers to using different cut-off points, and the results shown in Table 6 provide good support to our policy identification strategy. The first column (Model 10 in the table) refers to a cut-off age that is still consistent with our identification strategy, since the proportion of children in secondary schools does show a discontinuity at age 11. The impact on sugar intakes, considering the sub-sample of children taking the morning snack, is not dissimilar from our baseline estimates (9.5 grams vs. 10.5 grams) and still significant. However, no impact is found in terms of morning snack frequencies on the full sample, a result that is not too surprising if one considers the visualization of the discontinuity 
in Figure 1, which is clearly set at age 12 on the INCA1 sample.

The remaining three columns of the table refer to placebo cut-off points. We restrict the sample to include only children aged 11 or above, so that the vast majority of our observations are in secondary schools, and are thus subject to the VM ban. There is no apparent reason to find discontinuities at older ages, and models with cut-offs at 13, 14, and 15 do not return any meaningful impact. The only significant impact (on snack frequency) has an opposite sign relative to the baseline model.

Taken together, our validation checks confirm that the VM ban has been effective in reducing morning snack frequencies among secondary school children and the average sugar intake of those taking the morning snack.

[Table 6 approximately here]

\section{Compensation Effects}

Our evidence suggests that the significant reduction in sugar intakes during the morning break is not necessarily maintained throughout the day, as no impact of the VM ban on daily intakes has been detected. As envisaged, this finding may be suggestive of compensation effects. Thus, we explore the impact of the vending machine ban during meal occasions other than the morning break, but focusing on three specific sub-samples: (1) those children who had a morning snack; (2) those children who had a morning snack and an afternoon snack; (3) those children who had an afternoon snack, but not a morning snack. For each of these groups, we search for potential compensation effects by looking at more specific outcome measures. The results are shown in Table $7 .{ }^{15}$

The first sample is our baseline group, with evidence of reduction in sugar intake during the morning snack. We look at their total daily sugar intake, and the intake from all meals 
except the morning snack. These further estimates show that the morning reduction is not sustained throughout the day, as the overall daily intake is non-significant and positive. Furthermore, an increase in sugar intake (significant at the 10 percent level) is observed outside the morning break meal occasion, a result that is consistent with the former.

Since our policy identification assumption rests on the hypothesis that the VM ban primarily affects school breaks, we check whether compensation may occur during the afternoon snack. Thus, we look at the afternoon snack intake for those children who already had a morning snack. Estimates are non-significant and close to zero in size, which indicates that any additional sugar intake comes from other meal occasions than the afternoon snack.

As a final test on compensation effects, we refer to the complementary sample of snackers, i.e., those children who take a snack in the afternoon only, and not in the morning. A reduction in sugar (again, significant at the 10 percent level) from this single snacking occasion is estimated on this sample, albeit smaller relative to the one estimated for the morning snack (8 grams vs. 10.5 in the baseline model). This could be seen as a further validation of our policy identification assumptions, as the afternoon snack is not guaranteed to be consumed at school. When looking at total daily intakes, the size effect is similar and even larger relative to the reduction observed during the afternoon snack, but not significant. Similarly, restricting the outcome measure to other meal occasions than (afternoon) snacking produces inconclusive results. While this might be suggestive that restrictions on snacks earlier in the day are more likely to induce compensation effects, the uncertainties regarding the location of the afternoon snacks prevent us from claiming a conclusive relation between the ban and these findings.

[Table 7 approximately here]

\section{DISCUSSION AND CONCLUSIONS}


We exploit the availability of data on nutrient intakes prior to and after the French ban of VMs from secondary schools to estimate the effect of the policy on morning snack-related intakes. The combination of a difference-in-difference approach with a regression discontinuity design has the double advantage of controlling for differences in unobservable factors and mitigating the effect of heterogeneity in children's nutritional demand at different ages. Since the ban only affected children when entering secondary schools, but exposure to the ban is not a deterministic function of age at the interview, we adopt a fuzzy design, and we test for the robustness of our results through a set of validation checks.

We provide some evidence that the VM ban has reduced both the sugar intake during morning breaks at school, as well as the frequency of these morning snacks. The reduction in sugar intakes is consistently estimated at around 10 grams (about one-third of an ounce or 38 calories). No detectable impact emerges for total calories, fats, and saturated fats. The effect on morning snack frequency is significant, with a reduction of about one snack every three school mornings per child relative to the counterfactual, considering all school children.

These results are robust to different choices on the age bandwidths around the cut-off point. We also tested for a different assumption on the discontinuity point, choosing 11 instead of 12 as the cut-off age-at-interview which proxies access to secondary school, and results were similar. Alternative placebo discontinuity points at 13,14 , and 15 returned no significant impact. The results were also robust to the introduction of covariates in the model or the adoption of a semi-parametric specification.

Our data allow repetition of the analysis on different meal occasions, and on total daily intakes. When considering all school children, including those not consuming morning snacks at school, no significant effect emerges. Thus, we find no detectable effect of the school VM ban on the average diet of French secondary school children, at least in its first two years of application. When we restrict the sample to those who actually consumed a morning snack at 
school, results are suggestive of compensation effects. On average, the effect on daily sugar intakes is still non-significant and switches from being negative to positive. Potential compensation effects on those who reduced sugar intakes in the morning also emerge when looking at the estimates considering all meal occasions except the morning snack. These results indicate a significant increase of sugar intakes, with a size effect that is larger than the morning reduction.

We also find that compensation does not occur during the afternoon snack. On the contrary, the evidence of the ban affecting snacking occasions is confirmed when the analysis is confined to those children who only take the afternoon snack. The estimated effects are significant but lower and these results need to be taken with caution, as an unknown proportion of these snacks may be consumed outside the school premises.

From a policy perspective, this study provides several insights. First, we extend and compare the existing evidence, previously limited to overall school bans, the U.S. and soft drink intakes, to consider the specific effect of a VM ban on nutrient intakes associated with any food or drink, and in a European setting. Similar to previous studies, our results suggest that school bans are effective in restricting behaviors on the school premises, but that their reach is limited when considering the overall diet. Interestingly, this finding mirrors evaluations of policies whose objectives potentially conflict with those of reducing intakes at school, namely the Breakfast in the Classroom (BIC) intervention which provides breakfast to school children at the start of the school day in many U.S. school districts. The program targets food insecurity and aims at improving school performances, but has been blamed as a potential cause of weight gain for children. However, a recent study on the New York City BIC by Corcoran et al. (2016) found no evidence of an increase in BMI of participating children, suggesting again that acting on morning intakes is only loosely associated with overall dietary behavior.

Second, the VM ban seems to be well-targeted, as our description of the French data 
confirms that VM users have — on average — a worse lifestyle than non-users. Not only are their calorie, sugar, and fat intakes higher, but they also more frequently consume fast food meals, drink more sodas, and spend more time on TVs and PCs.

Third, although our study is not conclusive in that respect, our results are in line with the notion that bans may be effective ways to control for behavioral failure in regulated environments, but that they fail to achieve the overarching goal if not accompanied by other interventions to nudge consumers towards better behaviors in less regulated environments. For our specific case, this consideration must be framed in a context where dietary improvements are observed in children of all ages, including primary school children who are not targeted by the VM ban. In other words, we are looking at the marginal impact of the ban after accounting for this general trend, which may also indicate that the broader policy mix acting on French school children is effective. Results from a separate school survey carried out in 2005 reported in Dubuisson et al. (2009) and Bertin et al. (2012) indicate that most schools have adopted school lunches with less high-fat products and more healthy alternatives. The same survey also shows that other forms of school food supplies were not subject to stringent restrictions and better compliance with the nutrition recommendations required the adoption of a new law in 2010.

An immediate policy implication of our findings within this broader context is that restrictions on school vending machines have a limited scope when implemented as a standalone policy. A better coordination of school-based policies is a necessary condition to their success, and there is a clear need to expand the scope of the policy toolbox to address potential compensating behaviors outside the school environment.

SARA CAPACCI is Lecturer in the Department of Economics at the University of Bologna, Via Angherà 22, 47921 Rimini, Italy (e-mail: sara_capacci@unibo.it). 
MARIO MAZZOCCHI is a Professor in the Department of Statistical Sciences at the University of Bologna, Via Belle Arti 41, 40126 Bologna, Italy (e-mail: m.mazzocchi@unibo.it).

BHAVANI SHANKAR is a Professor at SOAS and the Leverhulme Centre for Integrative Research in Agriculture and Health at the University of London, 36 Gordon Square, London, UK(e-mail: bs33@soas.ac.uk).

\section{ACKNOWLEDGMENTS}

The research leading to these results has received funding from the European Union Seventh Framework Programme (FP7) under grant agreement n. 226713, EATWELL project. We are especially grateful to Carine Dubuisson and Jean-Luc Volatier of the French authority ANSES for providing the data and background information. We also wish to thank Tim Beatty for his precious comments on an earlier version of this paper, Bruce Traill, Xavier Irz and all participants to the Eatwell project for their feedback and suggestions. Finally, we thank the Editor-in-Chief Kenneth Couch, the co-Editor Jason Fletcher and three anonymous reviewers for their careful reading and constructive comments. Any error should be obviously imputed to the authors only.

\section{REFERENCES}

Anderson, G. H., \& Woodend, D. (2003). Consumption of sugars and the regulation of shortterm satiety and food intake. The American Journal of Clinical Nutrition, 78, 843S-849S.

Anderson, P. M. \& Butcher, K. F. (2006). Reading, writing, and refreshments: Are school finances contributing to children's obesity? Journal of Human Resources, 41, 467-494.

Bellisle, F., Drewnowski, A., Anderson, G. H., Westerterp-Plantenga, M., \& Martin, C. K. (2012). Sweetness, satiation, and satiety. The Journal of Nutrition, 142, 1149S-1154S.

Bertin, M., Lafay, L., Calamassi-Tran, G., Volatier, J.-L., \& Dubuisson, C. (2012). School 
meals in French secondary state schools: Do national recommendations lead to healthier nutrition on offer? British Journal of Nutrition, 107, 416-427.

Bocquet, A., Bresson, J.-L., Briend, A., Chouraqui, J.-P., Darmaun, D., Dupont, ... \& Vidailhet, M. (2003). La collation de 10 heures en milieu scolaire: Un apport alimentaire inadapté et superflu. Archives de Pédiatrie, 10, 945-947.

Cattaneo, M. D., Titiunik, R., \& Vazquez-Bare, G. (2017). Comparing inference approaches for RD designs: A reexamination of the effect of Head Start on child mortality. Journal of Policy Analysis and Management, 36, 643-681.

Chaloupka, F. J., Powell, L. M., \& Chriqui, J. F. (2011). Sugar-sweetened beverages and obesity: The potential impact of public policies. Journal of Policy Analysis and Management, 30, 645-655.

Chauliac, M. \& Hercberg, S. (2012). Changing the food environment: the French experience. Advances in Nutrition: An International Review Journal, 3, 605s-610s.

Corcoran, S. P., Elbel, B., \& Schwartz, A. E. (2016). The effect of breakfast in the classroom on obesity and academic performance: Evidence from New York City. Journal of Policy Analysis and Management, 35, 509-532.

Cradock, A. L., McHugh, A., Mont-Ferguson, H., Grant, L., Barrett, J. L., Wang, Y. C., \& Gortmaker, S. L. (2011). Effect of school district policy change on consumption of sugarsweetened beverages among high school students, Boston, Massachusetts, 2004-2006. 
Preventing Chronic Disease, 8, A74.

Datar, A. \& Nicosia, N. (2012). Junk food in schools and childhood obesity. Journal of Policy Analysis and Management, 2, 312-337.

Drewnowski, A. \& Bellisle, F. (2007). Liquid calories, sugar, and body weight. The American Journal of Clinical Nutrition, 85, 651-661.

Driessen, C. E., Cameron, A. J., Thornton, L. E., Lai, S. K., \& Barnett, L. M. (2014). Effect of changes to the school food environment on eating behaviours and/or body weight in children: A systematic review. Obesity Reviews, 15, 968-982.

Dubuisson, C., Lioret, S., Calamassi-Tran, G., Volatier, J.-L., \& Lafay, L. (2009). School meals in French secondary state schools with regard to the national recommendations. British Journal of Nutrition, 102, 293-301.

Dubuisson, C., Lioret, S., Dufour, A., Calamassi-Tran, G., Volatier, J.-L., Lafay, L., \& Turck, D. (2015). The relationship between school lunch attendance and the food intakes of French schoolchildren aged 3-17 years. Public Health Nutrition, 18, 1647-1657.

Dubuisson, C., Lioret, S., Touvier, M., Dufour, A., Calamassi-Tran, G., Volatier, J.-L. \& Lafay, L.(2010). Trends in food and nutritional intakes of French adults from 1999 to 2007: Results from the INCA surveys. British Journal of Nutrition, 103, 1035.

Fan, J. \& Gijbels, I. (1996). Local polynomial modelling and its applications. Monographs on 
Statistics and Applied Probability 66. Boca Raton, FL: Chapman \& Hall.

Fletcher, J. M., Frisvold, D., \& Tefft, N. (2010). Taxing soft drinks and restricting access to vending machines to curb child obesity. Health Affairs, 29, 1059-1066.

Fletcher, J. M., Frisvold, D. E., \& Tefft, N. (2011). Are soft drink taxes an effective mechanism for reducing obesity? Journal of Policy Analysis and Management, 30, 655-662.

Hahn, J., Todd, P., \& Van der Klaauw, W. (2001). Identification and estimation of treatment effects with a regression-discontinuity design. Econometrica, 69, 201-209.

Hercberg, S., Chat-Yung, S., \& Chauliac, M. (2008). The French National Nutrition and Health Program: 2001-2006-2010. International Journal of Public Health, 53, 68-77.

Huang, R. \& Kiesel, K. (2012). Does limited access at school result in compensation at home? The effect of soft drink bans in schools on purchase patterns outside of schools. European Review of Agricultural Economics, 39, 797-820.

Ikeda, M. \& García, E. (2013). Grade repetition: A comparative study of academic and nonacademic consequences. OECD Journal: Economic Studies, 2013/1, 269-315.

Imbens, G. W. \& Lemieux, T. (2008). Regression discontinuity designs: A guide to practice. Journal of Econometrics, 142, 615-635.

Johnston, L. D., Delva, J., \& O’Malley, P. M. (2007). Soft drink availability, contracts, and 
revenues in American secondary schools. American Journal of Preventive Medicine, 33, S209-S225.

Kocken, P. L., Eeuwijk, J., Van Kesteren, N., Dusseldorp, E., Buijs, G., Bassa-Dafesh, Z., \& Snel, J. (2012). Promoting the purchase of low-calorie foods from school vending machines: A cluster-randomized controlled study. Journal of School Health, 82, 115-122.

Larson, N. \& Story, M. (2013). A review of snacking patterns among children and adolescents: What are the implications of snacking for weight status? Childhood Obesity, 9, 104-115.

Lee, D. S. \& Lemieux, T. (2010). Regression discontinuity designs in economics. Journal of Economic Literature, 48, 281-355.

Lioret, S., Dubuisson, C., Dufour, A., Touvier, M., Calamassi-Tran, G., Maire, B., Volatier, J.-L., \& Lafay, L. (2010). Trends in food intake in French children from 1999 to 2007: Results from the INCA dietary surveys. British Journal of Nutrition, 103, 585-601.

Lioret, S., Touvier, M., Dubuisson, C., Dufour, A., Calamassi-Tran, G., Lafay, L., Volatier, J.-L., \& Maire, B. (2009). Trends in child overweight rates and energy intake in France from 1999 to 2007: Relationships with socioeconomic status. Obesity, 17, 1092-1100.

Ludwig, J. \& Miller, D. L. (2007). Does Head Start improve children's life chances? Evidence from a regression discontinuity design. The Quarterly Journal of Economics, 122, 159-208.

Malik, V. S., Pan, A., Willett, W. C., \& Hu, F. B. (2013). Sugar-sweetened beverages and 
weight gain in children and adults: A systematic review and meta-analysis. The American Journal of Clinical Nutrition, 98, 1084-1102.

Mello, M. M., Pomeranz, J., \& Moran, P. (2008). The interplay of public health law and industry self-regulation: The case of sugar-sweetened beverage sales in schools. American Journal of Public Health, 98, 595-604.

Ng, M., Fleming, T., Robinson, M., Thomson, B., Graetz, N., Margono, C., Mullany, E.C., ...\& Gakidou, E. (2014). Global, regional, and national prevalence of overweight and obesity in children and adults during 1980-2013: A systematic analysis for the Global Burden of Disease Study 2013. Lancet, 384, 766-781.

Ogden, C. L., Carroll, M. D., Lawman, H. G., Fryar, C. D., Kruszon-Moran, D., Kit, B. K., \& Flegal, K. M. (2016). Trends in obesity prevalence among children and adolescents in the United States, 1988-1994 through 2013-2014. Journal of the American Medical Association, 315, 2292-2299.

Pasch, K. E., Lytle, L. A., Samuelson, A. C., Farbakhsh, K., Kubik, M. Y., \& Patnode, C. D. (2011). Are school vending machines loaded with calories and fat: An assessment of 106 middle and high schools. Journal of School Health, 81, 212-218.

Piernas, C. \& Popkin, B. M. (2010). Trends in snacking among U.S. children. Health Affairs, 29, 398-404.

Rovner, A. J., Nansel, T. R., Wang, J., \& Iannotti, R. J. (2011). Food sold in school vending 
machines is associated with overall student dietary intake. Journal of Adolescent Health, 48, $13-19$.

Story, M., Nanney, M. S., \& Schwartz, M. B. (2009). Schools and obesity prevention: Creating school environments and policies to promote healthy eating and physical activity. Milbank Quarterly, 87, 71-100.

Taber, D. R., Chriqui, J. F., Powell, L. M., \& Chaloupka, F. J. (2012). Banning all sugarsweetened beverages in middle schools: Reduction of in-school access and purchasing but not overall consumption. Archives of Pediatrics \& Adolescent Medicine, 166, 256-262.

Taber, D. R., Chriqui, J. F., Vuillaume, R., \& Chaloupka, F. J. (2014). How state taxes and policies targeting soda consumption modify the association between school vending machines and student dietary behaviors: A cross-sectional analysis. PLoS ONE, 9, 1-8.

Te Morenga, L., Mallard, S., \& Mann, J. (2013). Dietary sugars and body weight: Systematic review and meta-analyses of randomised controlled trials and cohort studies. British Medical Journal, 346, e7492.

Terry-McElrath, Y. M., Johnston, L. D., \& O’Malley, P. M. (2012). Trends in competitive venue beverage availability: Findings from U.S. secondary schools. Archives of Pediatrics \& Adolescent Medicine, 166, 776-778. 
Table 1. Summary statistics from the INCA1 (1998/1999) and INCA2 (2006/2007) surveys.

\begin{tabular}{|c|c|c|c|c|}
\hline & \multicolumn{2}{|c|}{ INCA 1 (pre-policy) } & \multicolumn{2}{|c|}{ INCA 2 (post-policy) } \\
\hline & Age 6-11 & Age $12-18$ & Age 6-11 & Age $12-18$ \\
\hline \multicolumn{5}{|l|}{ Outcomes (average per individual per day) } \\
\hline & & Mid-mo & ling break & \\
\hline \multirow[t]{2}{*}{ Energy intake (Kcal) } & 177.27 & 197.30 & 152.19 & 162.41 \\
\hline & $(104.46)$ & (127.08) & (104.57) & $(147.31)$ \\
\hline \multirow[t]{2}{*}{ Sugar intake $(\mathrm{g})$} & 15.83 & 21.80 & 14.52 & 13.32 \\
\hline & (12.16) & (18.69) & (10.47) & (13.98) \\
\hline \multirow[t]{2}{*}{ Fat intake $(g)$} & 6.60 & 7.64 & 5.67 & 6.28 \\
\hline & $(5.57)$ & $(8.30)$ & $(5.27)$ & (7.70) \\
\hline \multirow[t]{2}{*}{ Saturated fat intake $(\mathrm{g})$} & 3.34 & 3.55 & 2.83 & 3.01 \\
\hline & (2.97) & $(3.65)$ & (2.68) & (4.19) \\
\hline \multirow[t]{2}{*}{ Morning snack frequency } & 0.21 & 0.11 & 0.26 & 0.16 \\
\hline & $(0.35)$ & $(0.26)$ & $(0.37)$ & $(0.28)$ \\
\hline \multirow[t]{2}{*}{$\mathrm{N}$} & 95 & 54 & 160 & 175 \\
\hline & \multicolumn{4}{|c|}{ All day } \\
\hline \multirow[t]{2}{*}{ Energy intake (Kcal) } & 1841.02 & 2009.36 & 1710.79 & 1873.69 \\
\hline & $(489.45)$ & $(709.81)$ & $(433.46)$ & $(609.86)$ \\
\hline \multirow[t]{2}{*}{ Sugar intake $(\mathrm{g})$} & 101.15 & 101.66 & 96.41 & 96.67 \\
\hline & (39.33) & $(51.96)$ & $(31.45)$ & (42.95) \\
\hline \multirow[t]{2}{*}{ Fat intake $(\mathrm{g})$} & 76.06 & 84.23 & 70.06 & 75.81 \\
\hline & (22.56) & (29.18) & $(21.26)$ & (27.59) \\
\hline \multirow[t]{2}{*}{ Saturated fat intake $(\mathrm{g})$} & 33.83 & 37.08 & 30.36 & 32.26 \\
\hline & (10.79) & (13.84) & $(9.81)$ & (12.87) \\
\hline $\mathrm{N}$ & 293 & 250 & 388 & 585 \\
\hline \multicolumn{5}{|l|}{ Other individual characteristics } \\
\hline \multirow[t]{2}{*}{ Age (years) } & 8.32 & 14.20 & 8.70 & 14.87 \\
\hline & $(1.67)$ & (1.96) & $(1.75)$ & $(1.76)$ \\
\hline \multirow[t]{2}{*}{ Proportion of female (\%) } & 0.00 & 0.01 & 0.01 & 0.01 \\
\hline & $(0.50)$ & $(0.50)$ & $(0.50)$ & $(0.50)$ \\
\hline \multirow[t]{2}{*}{ Height (cm) } & 130.78 & 161.11 & 132.63 & 164.38 \\
\hline & (12.23) & $(10.42)$ & (12.46) & $(10.15)$ \\
\hline \multirow[t]{2}{*}{ Weight (kg) } & 29.71 & 51.53 & 30.26 & 55.66 \\
\hline & $(8.65)$ & (11.53) & $(8.81)$ & (13.26) \\
\hline \multirow[t]{2}{*}{ Household size } & 4.16 & 4.17 & 4.14 & 3.96 \\
\hline & $(0.82)$ & $(0.81)$ & $(0.94)$ & (1.13) \\
\hline \multirow[t]{2}{*}{ Soda intake (ml per day) } & 24.76 & 62.71 & 18.79 & 50.10 \\
\hline & (47.41) & $(88.00)$ & $(37.32)$ & (83.08) \\
\hline \multirow[t]{2}{*}{ Fast food at least once a week (\%) } & & & $4.77 \%$ & $14.75 \%$ \\
\hline & & & (21.35) & (35.48) \\
\hline \multirow[t]{2}{*}{ Daily TV or PC screen time (min) } & & & 138.22 & 205.28 \\
\hline & & & (102.99) & $(138.20)$ \\
\hline \multirow[t]{2}{*}{ Usually goes to school by bike or foot (\%) } & & & $38.58 \%$ & $33.86 \%$ \\
\hline & & & $(48.74)$ & $(47.42)$ \\
\hline
\end{tabular}

Notes: Standard deviations in parentheses. Mean intakes per child during morning breaks are computed as the average of morning breaks with non-zero calories. Children reporting zero calories for all morning breaks do not enter the sample. The morning snack frequency is defined as the ratio between the number of morning snacks with non-zero calories and the number of valid school-day records per child. 
Table 2. Use of vending machines, nutrient intakes, and selected behaviors of school children (INCA2 survey, 2006/2007).

\begin{tabular}{|c|c|c|c|c|}
\hline & \multicolumn{4}{|c|}{ Sample } \\
\hline & \multicolumn{2}{|c|}{ All school levels } & \multicolumn{2}{|c|}{ Secondary school only } \\
\hline & \multicolumn{4}{|c|}{ Use of vending machines } \\
\hline & Non-users & Users & Non-users & Users \\
\hline & \multicolumn{4}{|c|}{ All day } \\
\hline Energy intake (Kcal) & $\begin{array}{l}1778.52 \\
(486.20)\end{array}$ & $\begin{array}{l}1809.69 \\
(502.63)\end{array}$ & $\begin{array}{c}1810.21 \\
(547.66)\end{array}$ & $\begin{array}{l}1825.63 \\
(517.39)\end{array}$ \\
\hline Sugar intake $(g)$ & $\begin{array}{c}95.02 \\
(33.75)\end{array}$ & $\begin{array}{c}96.99 \\
(36.87)\end{array}$ & $\begin{array}{c}93.62 \\
(38.68)\end{array}$ & $\begin{array}{c}95.49 \\
(38.24)\end{array}$ \\
\hline Fat intake $(\mathrm{g})$ & $\begin{array}{l}70.98 \\
(21.46)\end{array}$ & $\begin{array}{c}73.87 \\
(23.34)\end{array}$ & $\begin{array}{l}71.97 \\
(24.09)\end{array}$ & $\begin{array}{c}74.51 \\
(24.08)\end{array}$ \\
\hline Saturated fat intake $(\mathrm{g})$ & $\begin{array}{l}30.41 \\
(9.88)\end{array}$ & $\begin{array}{l}31.48 \\
(11.00)\end{array}$ & $\begin{array}{c}30.51 \\
(10.90)\end{array}$ & $\begin{array}{c}31.49 \\
(11.29)\end{array}$ \\
\hline Morning snack frequency & $\begin{array}{c}0.19 \\
(0.32)\end{array}$ & $\begin{array}{c}0.19 \\
(0.30)\end{array}$ & $\begin{array}{c}0.49 \\
(0.26)\end{array}$ & $\begin{array}{c}0.52 \\
(0.27)\end{array}$ \\
\hline Soda intake $(\mathrm{ml})$ & $\begin{array}{c}27.33 \\
(58.15)\end{array}$ & $\begin{array}{c}63.7 \\
(88.70)\end{array}$ & $\begin{array}{c}35.86 \\
(72.30)\end{array}$ & $\begin{array}{c}77.45 \\
(94.53)\end{array}$ \\
\hline Fast food at least once a week (\%) & $\begin{array}{l}8.45 \% \\
(0.28)\end{array}$ & $\begin{array}{c}15.05 \% \\
(0.36)\end{array}$ & $\begin{array}{c}11.67 \% \\
(0.32)\end{array}$ & $\begin{array}{c}18.42 \% \\
(0.39)\end{array}$ \\
\hline \multirow[t]{2}{*}{ Daily TV or PC screen time (min) } & $\begin{array}{c}164.56 \\
(122.48)\end{array}$ & $\begin{array}{c}186.94 \\
(123.58)\end{array}$ & $\begin{array}{c}190.37 \\
(131.41)\end{array}$ & $\begin{array}{c}206.54 \\
(125.53)\end{array}$ \\
\hline & \multicolumn{4}{|c|}{ Proportion of users by school level $(\%)$} \\
\hline All children (age 6-18) & $72.78 \%$ & $27.22 \%$ & & \\
\hline Primary school & $83.94 \%$ & $16.06 \%$ & & \\
\hline Middle school & $71.49 \%$ & $28.51 \%$ & & \\
\hline High school & $59.03 \%$ & $40.97 \%$ & & \\
\hline $\mathrm{N}$ & 556 & 206 & 300 & 152 \\
\hline
\end{tabular}

Notes: Standard deviations in parentheses. Users of vending machine are defined as those who state they purchase food or drinks from a vending machine at least once a week. 
Table 3. Effect on intakes and snacking frequencies during the morning school break (baseline model).

\begin{tabular}{lcccc}
\hline & \multicolumn{5}{c}{ Bandwidth (age) } \\
Outcome & $6-18$ & $7-17$ & $8-16$ & $9-15$ \\
\hline \multirow{3}{*}{ Energy intake (Kcal) } & \multicolumn{5}{c}{ Average intakes per child per break } \\
& -22.201 & -9.536 & $\mathbf{- 1 3 . 6 0 9}$ & -58.199 \\
Sugar intake (g) & $(31.814)$ & $(32.776)$ & $\mathbf{( 3 8 . 9 5 1 )}$ & $(40.684)$ \\
& $-9.544 * *$ & $-11.657 * * *$ & $-11.559 * *$ & $\mathbf{- 1 0 . 4 4 8 *}$ \\
Fat intake (g) & $(4.000)$ & $(4.474)$ & $(5.307)$ & $\mathbf{( 6 . 0 1 7 )}$ \\
& -0.763 & 0.183 & $\mathbf{0 . 1 4 2}$ & -2.21 \\
Saturated fat intake (g) & $(1.910)$ & $(1.720)$ & $\mathbf{( 2 . 1 3 9 )}$ & $(2.102)$ \\
& -0.244 & 0.137 & $\mathbf{- 0 . 0 2 7}$ & -1.178 \\
N & $(0.911)$ & $(0.939)$ & $\mathbf{( 1 . 1 8 5 )}$ & $(1.014)$ \\
& 484 & 413 & 299 & 216 \\
Morning snack frequency & $-0.257 * * *$ & $\mathbf{- 0 . 2 2 8} * * *$ & $-0.324 * * *$ & $-0.374 * * *$ \\
& $(0.077)$ & $\mathbf{( 0 . 0 7 7 )}$ & $(0.103)$ & $(0.143)$ \\
$\mathrm{N}$ & 1517 & 1361 & 1111 & 884 \\
\hline
\end{tabular}

Notes: Optimal bandwidths in bold. Robust standard errors in parentheses. Average intakes per child refer to morning breaks with non-zero calories. The morning snack frequency is defined as the ratio between the number of morning snacks with non-zero calories and the number of valid school-day records per child, and is computed on the full sample.

$* p<0.1 ; * * p<0.05 ; * * * p<0.01$. 
Table 4. Validation checks: Robustness to model specification (morning break impacts).

\begin{tabular}{|c|c|c|c|c|}
\hline \multirow[b]{3}{*}{ Outcome } & \multicolumn{4}{|c|}{ Model } \\
\hline & (1) & (2) & (3) & (4) \\
\hline & Baseline model & Semi-parametric & With Covariates & Sharp RDD \\
\hline & \multicolumn{4}{|c|}{ Average intakes per child per break } \\
\hline \multirow[t]{2}{*}{ Energy intake (Kcal) } & -13.609 & -18.945 & -18.848 & -9.613 \\
\hline & $(38.951)$ & $(32.785)$ & $(39.307)$ & $(30.597)$ \\
\hline \multirow[t]{2}{*}{ Sugar intake $(g)$} & $-10.448 *$ & $-8.957 * *$ & $-10.093 *$ & $-8.483^{*}$ \\
\hline & $(6.017)$ & $(4.122)$ & $(6.103)$ & $(4.571)$ \\
\hline \multirow[t]{2}{*}{ Fat intake $(\mathrm{g})$} & 0.142 & -0.874 & 0.031 & 0.148 \\
\hline & $(2.139)$ & $(1.975)$ & $(2.128)$ & $(1.638)$ \\
\hline \multirow[t]{3}{*}{ Saturated fat intake $(\mathrm{g})$} & -0.027 & -0.322 & -0.152 & 0.030 \\
\hline & $(1.185)$ & $(0.959)$ & $(1.183)$ & $(0.892)$ \\
\hline & \multicolumn{4}{|c|}{ Frequencies } \\
\hline \multirow[t]{2}{*}{ Morning snack frequency } & $-0.228 * * *$ & $-0.229 * * *$ & $-0.249 * * *$ & $-0.167 * * *$ \\
\hline & $(0.077)$ & $(0.076)$ & $(0.079)$ & $(0.057)$ \\
\hline
\end{tabular}

Notes: Robust standard errors in parentheses. Average intakes per child refer to morning breaks with non-zero calories. The morning snack frequency is defined as the ratio between the number of morning snacks with nonzero calories and the number of valid school-day records per child, and is computed on the full sample. Model (1): Baseline model, FD-RDD with cut-off at 12, optimal bandwidths.

Model (2): Kernel-weighted local polynomial regression, estimation sample 6-18.

Model (3): Baseline model with gender, height, weight, household size as additional covariates, optimal bandwidths.

Model (4): Sharp differenced regression discontinuity design, optimal bandwidths.

Estimates from models (2), (3), and (4) for all bandwidths are provided in the Appendix. ${ }^{16}$

$* \mathrm{p}<0.1 ; * * \mathrm{p}<0.05 ; * * * \mathrm{p}<0.01$. 
Table 5. Validation checks: Impact on different meal occasions.

\begin{tabular}{lccccc}
\hline & $(5)$ & $(6)$ & $(7)$ & $(8)$ & $(9)$ \\
Outcome & Morning \& Afternoon & Afternoon & Lunch & Dinner & All day \\
\hline \multirow{5}{*}{ Energy intake (Kcal) } & -45.934 & -29.639 & -43.622 & -23.182 & -13.175 \\
& $(45.870)$ & $(44.556)$ & $(45.902)$ & $(38.213)$ & $(88.579)$ \\
Sugar intake (g) & $-9.271 * * *$ & -5.647 & 2.103 & -1.126 & 0.489 \\
& $(3.587)$ & $(3.455)$ & $(2.111)$ & $(2.509)$ & $(6.558)$ \\
Fat intake (g) & -1.060 & -1.309 & -1.400 & -2.393 & -6.702 \\
& $(2.071)$ & $(1.952)$ & $(2.478)$ & $(2.515)$ & $(4.881)$ \\
Saturated fat intake $(\mathrm{g})$ & -0.795 & -0.774 & -0.881 & -1.629 & $-3.801 *$ \\
& $(0.994)$ & $(0.963)$ & $(1.107)$ & $(1.127)$ & $(2.272)$ \\
Snack frequencies & $-0.374 * * *$ & Frequencies & & \\
& $(0.143)$ & -0.168 & & \\
& \multicolumn{5}{c}{$(0.113)$} \\
\hline
\end{tabular}

Notes: Robust standard errors in parentheses. Estimates based on optimal bandwidths, estimates on other bandwidths are provided in the Appendix. ${ }^{17}$ Average intakes per child refer to the relevant meal occasions with non-zero calories. Snack frequencies are the ratio between the number of morning (afternoon) snacks with nonzero calories and the number of valid school-day records per child.

Model (5): Impact on total morning and afternoon snack intakes.

Model (6): Impact on afternoon snack intakes, sample excludes children with zero calories from the afternoon break.

Model (7): Impact on lunch intakes.

Model (8): Impact on dinner intakes.

Model (9): Impact on total daily intakes.

$* \mathrm{p}<0.1 ; * * \mathrm{p}<0.05 ; * * * \mathrm{p}<0.01$. 
Table 6. Validation checks: Impact at different cut-off ages.

\begin{tabular}{lcccc}
\hline & $(10)$ & $(11)$ & $(12)$ & $(13)$ \\
Outcome & Cut-off 11 & Cut-off 13 & Cut-off 14 & Cut-off 15 \\
\hline \multirow{2}{*}{ Everage } & intakes per child per meal & occasion $(s)$ \\
& -16.979 & -85.547 & -13.042 & -26.802 \\
Sugar intake (g) & $(35.386)$ & $(52.721)$ & $(37.503)$ & $(49.322)$ \\
& $-9.543^{* *}$ & -4.176 & 2.423 & 0.886 \\
Fat intake (g) & $(4.087)$ & $(6.118)$ & $(5.874)$ & $(6.305)$ \\
& -0.574 & -2.253 & -1.260 & -2.960 \\
Saturated fat intake (g) & $(1.893)$ & $(2.566)$ & $(1.969)$ & $(3.277)$ \\
& -0.192 & -1.336 & -1.195 & -1.620 \\
& $(0.972)$ & $(1.334)$ & $(1.101)$ & $(1.498)$ \\
Morning snack frequency & -0.037 & -0.068 & 0.037 & $0.097 * *$ \\
& $(0.048)$ & $(0.043)$ & $(0.035)$ & $(0.038)$ \\
\hline
\end{tabular}

Notes: Robust standard errors in parentheses. Average intakes per child refer to morning breaks with non-zero calories. The morning snack frequency is defined as the ratio between the number of morning snacks with nonzero calories and the number of valid school-day records per child, and is computed on the full sample. Estimates of model (10) for all feasible bandwidths are provided in the Appendix. ${ }^{18}$ Estimation samples for models (11), (12), and (13) exclude children aged below 11 and estimates are based on the only feasible bandwidth per model as detailed below.

Model (10): Optimal bandwidths.

Model (11): Bandwidth 11-15 (sample sizes $\mathrm{N}=150$ for average intakes, $\mathrm{N}=651$ for frequencies).

Model (12): Bandwidth 11-17 (sample sizes N=245 for average intakes, $\mathrm{N}=913$ for frequencies).

Model (13): Bandwidth 12-18 (sample sizes $\mathrm{N}=229$ for average intakes, $\mathrm{N}=835$ for frequencies).

$* \mathrm{p}<0.1 ; * * \mathrm{p}<0.05 ; * * * \mathrm{p}<0.01$. 
Table 7. Compensation effects, snacks, and sugar intakes.

\begin{tabular}{lccc}
\hline Sample of children: & Snack & All day & Outside snack \\
\hline Taking the morning snack (baseline) & $-10.448^{*}$ & 17.363 & $28.798^{*}$ \\
& $(6.017)$ & $(17.030)$ & $(14.893)$ \\
Taking both the morning and afternoon snack & -1.245 & 7.426 & 12.863 \\
& $(5.925)$ & $(12.560)$ & $(9.563)$ \\
Taking the afternoon snack only & $-8.081^{*}$ & -12.607 & -3.233 \\
& $(4.243)$ & $(11.000)$ & $(9.108)$ \\
\hline
\end{tabular}

Notes: Robust standard error in parentheses. Results reported for the optimal bandwidths. Results for other bandwidths and nutrients are reported in the Appendix. ${ }^{19}$ Impacts are estimated only on days where the relevant snacks are consumed. Snack intake for those taking both the morning and afternoon snack refers to the impact on sugar intake from the afternoon snack only. Outside snack intake for those taking the morning snack (baseline) refers to the impact on sugar intake from all meals except the morning snack. Outside snack for those taking both the morning and afternoon snack refers to the impact on sugar intake from all meals except the snacks (morning and afternoon).

$* \mathrm{p}<0.1 ; * * \mathrm{p}<0.05 ; * * * \mathrm{p}<0.01$ 
Figure 1. Average Outcomes by Age at the Interview.

\section{Calorie intake}
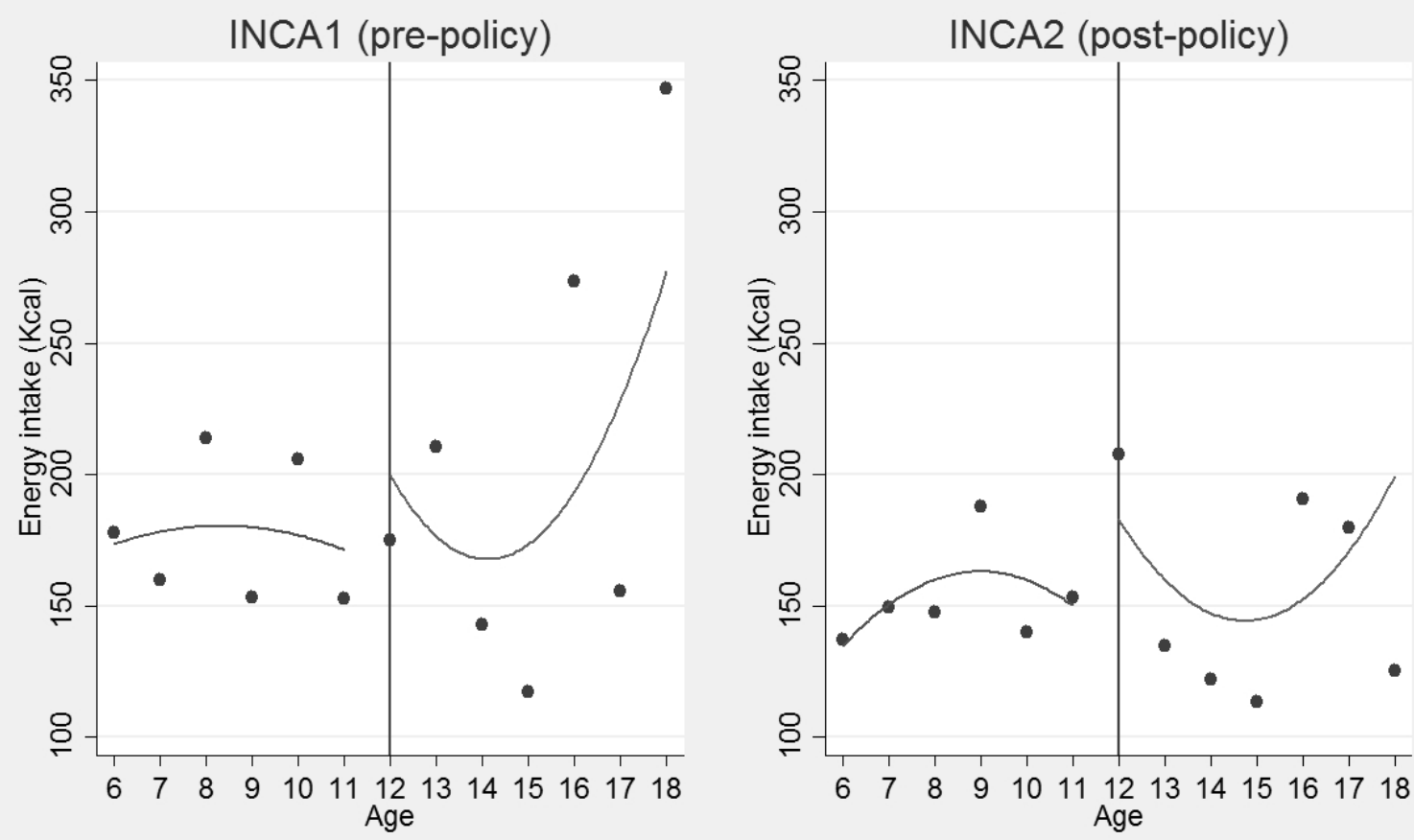

- Average intake by age

Quadratic fit (on all observations)

\section{Sugar intake}

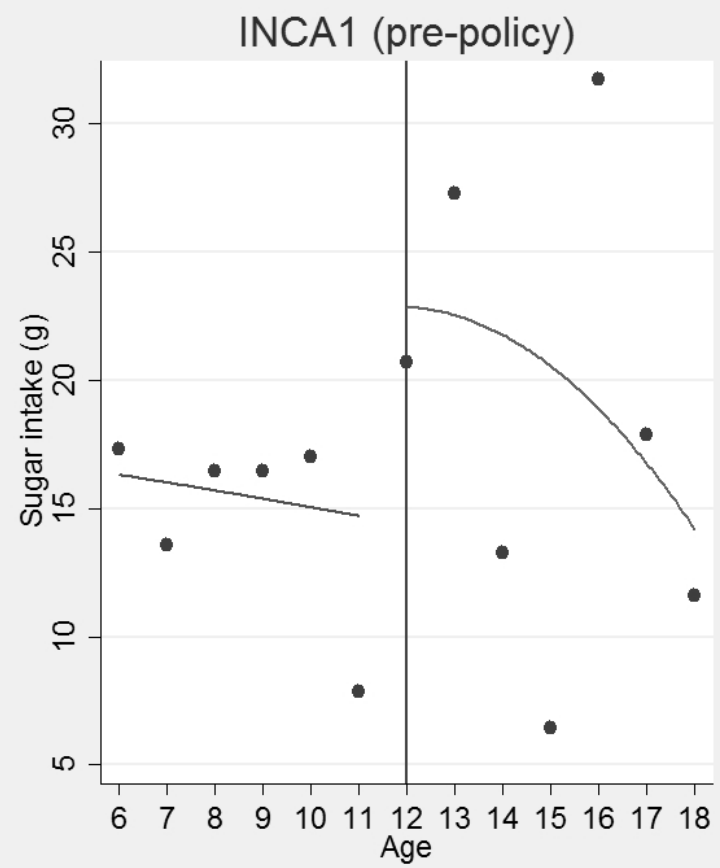

INCA2 (post-policy)

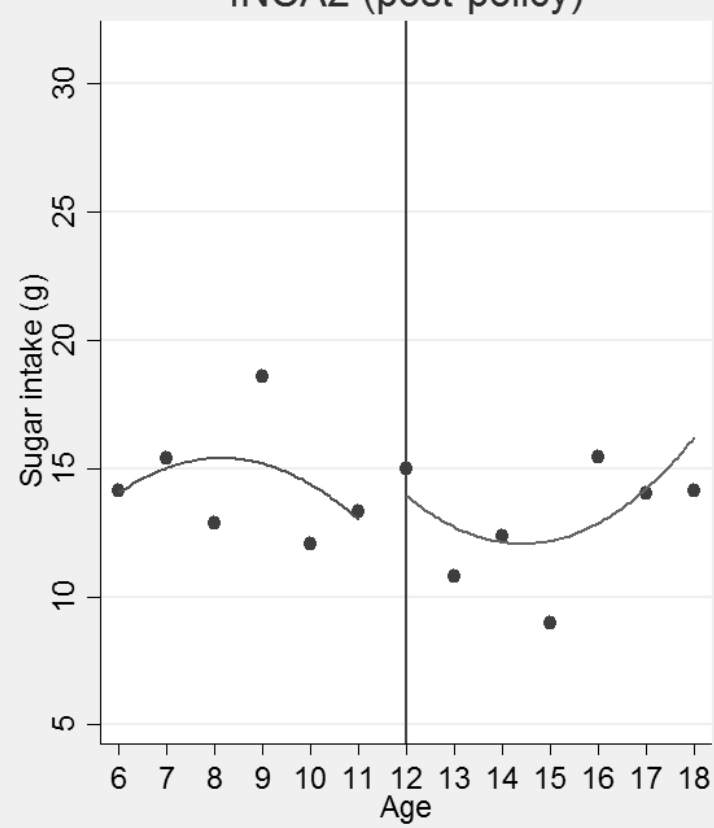

Average intake by age

Quadratic fit (on all observations) 


\section{Fat intake}
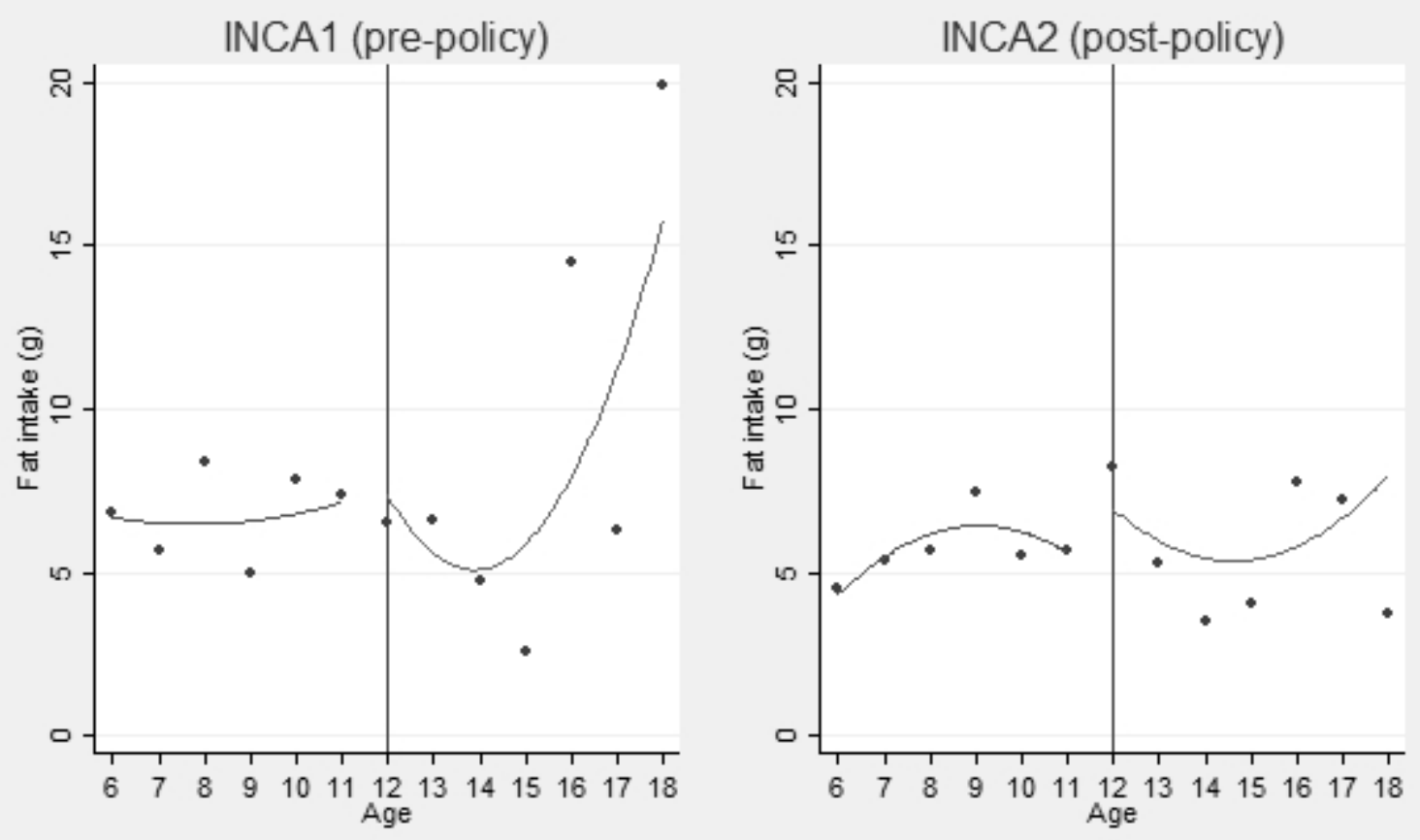

- Average intake by age

Quadratic fit (on all observations)

\section{Saturated fat intake}
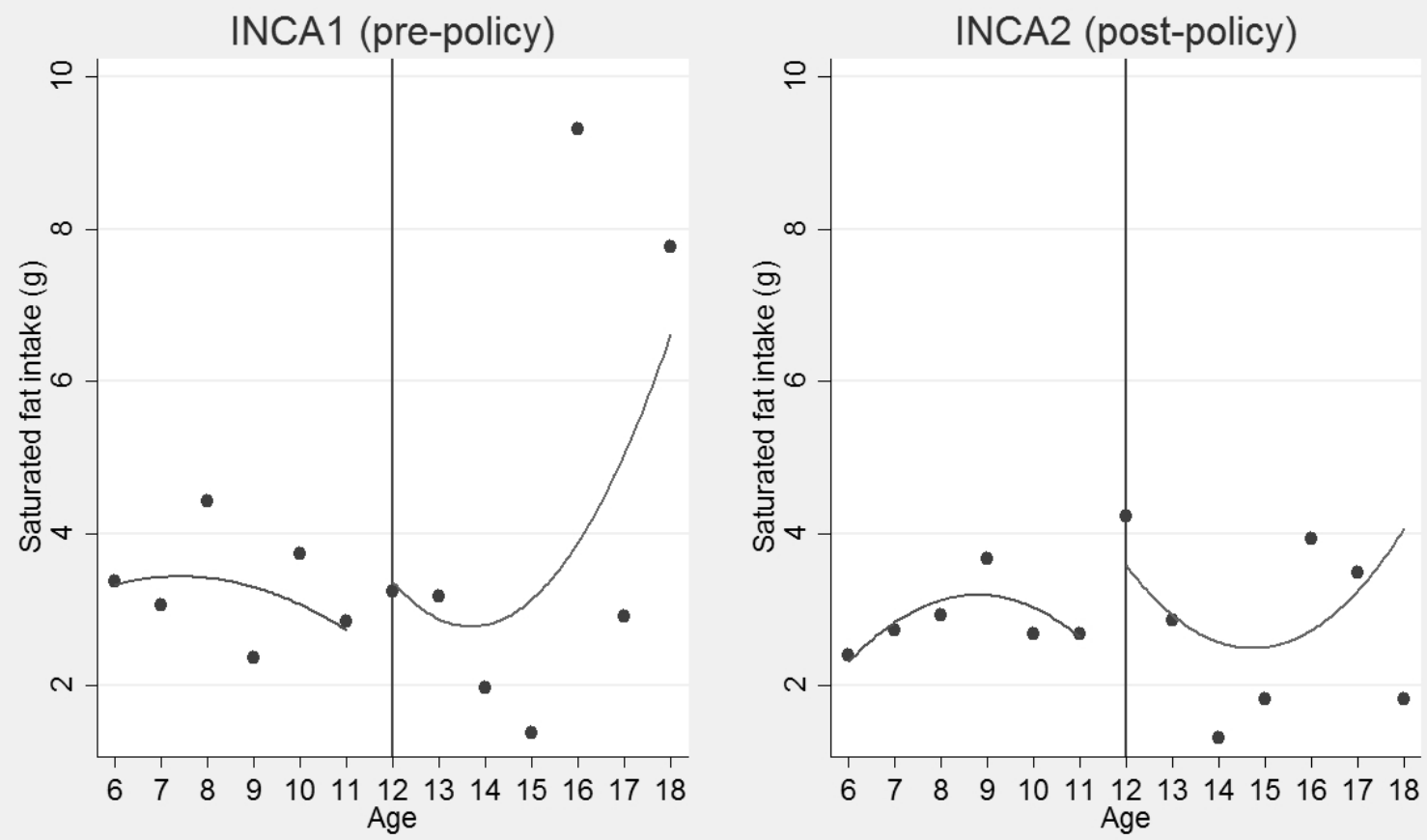

- Average intake by age

\section{Quadratic fit (on all observations)}




\section{Morning snack frequency}
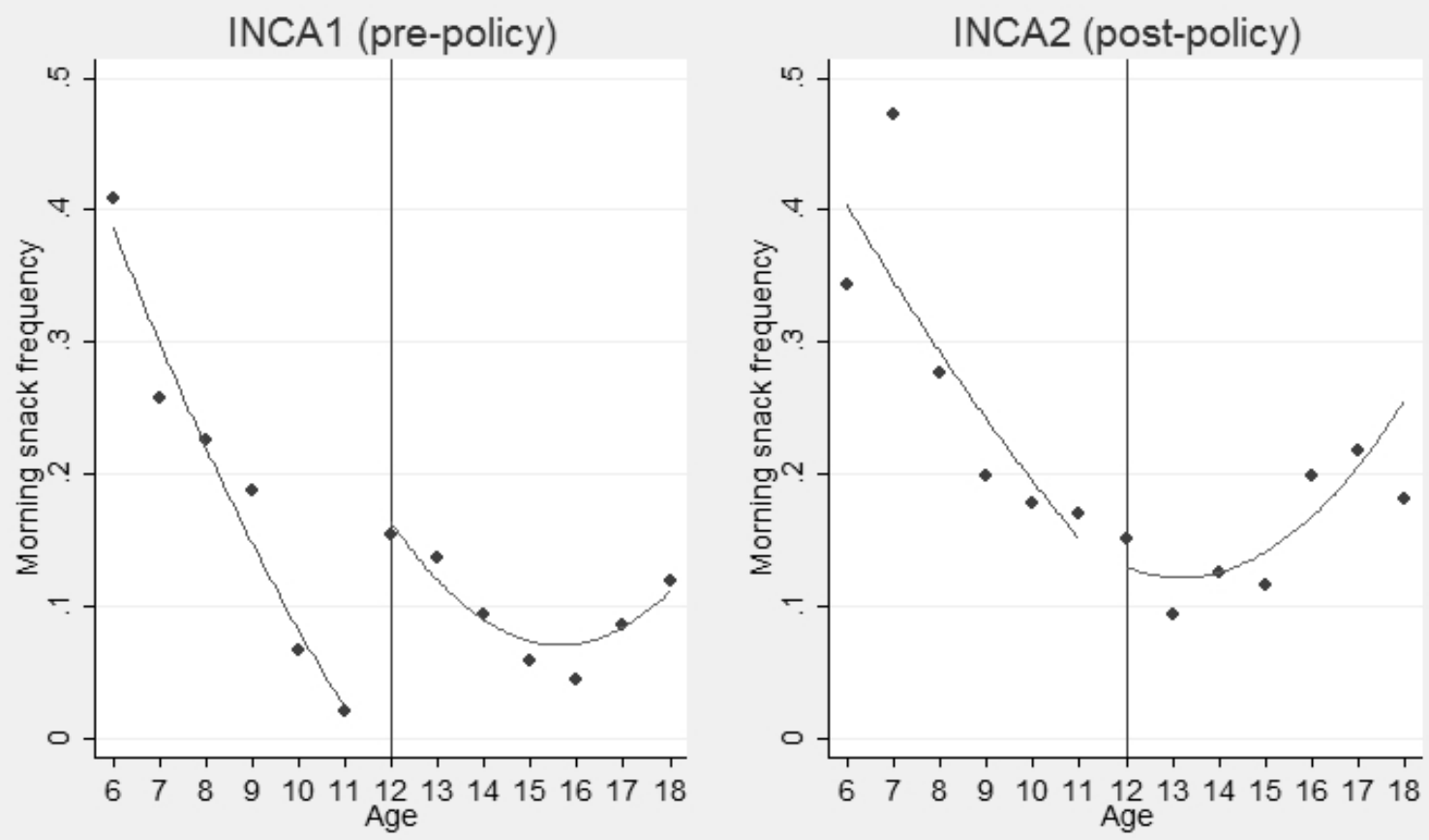

- Average frequency by age

Quadratic fit (on all observations) 


\section{APPENDIX}

\section{SUPPLEMENTARY OUTPUTS}

\section{Contents}

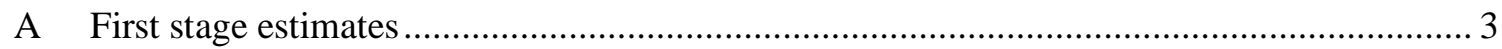

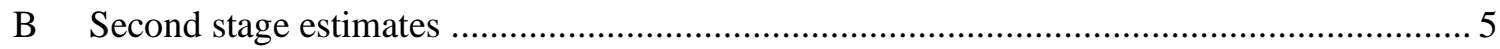

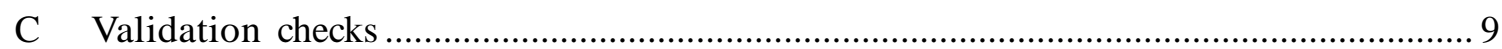

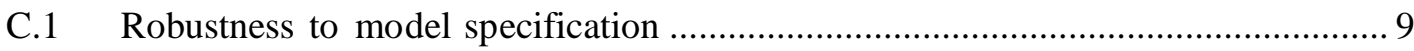

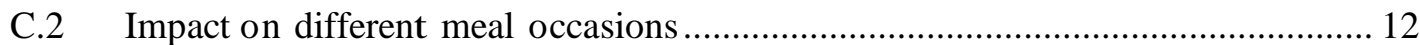

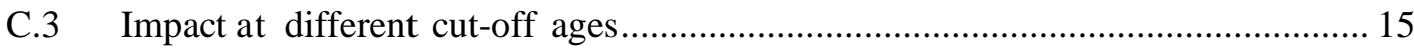

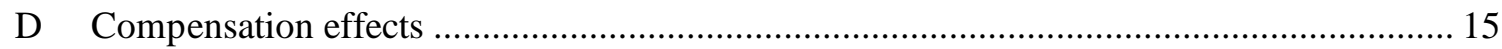

\section{List of Tables}

Table A1. First stage estimates: OLS versus Logit results, cut-off 12, all bandwidths. ................ 3

Table A2. Second stage estimates: baseline model using Logit models at the first stage, cut-off 12 , all bandwidths.

Table B1. Second stage estimates, bandwidth 6-18, full results ............................................... 5

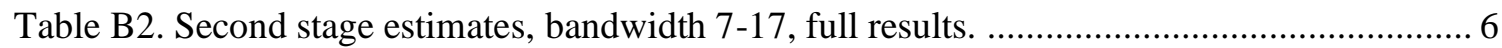

Table B3. Second stage estimates, bandwidth 8-16, full results. ............................................... 7

Table B4. Second stage estimates, bandwidth 9-15, full results. .............................................. 8

Table C1. Model (2): Kernel-weigthed local polynomial regression, all bandwidths. .................. 9

Table C2. Model (3): Baseline model with gender, height, weight, household size as additional covariates, all bandwidths

Table C3. Model (4): Sharp differenced regression discontinuity design, all bandwidths. ......... 11

Table C4. Model (5): Impact on total morning and afternoon snack intakes, all bandwidths. ... 12 
Table C5. Model (6): Impact on afternoon snack intakes (the sample excludes children with zero calories from the afternoon snack), all bandwidths.

Table C6. Model (7): Impact on lunch intakes, all bandwidths.. 13

Table C7. Model (8): Impact on dinner intakes, all bandwidths. 14

Table C8. Model (9): Impact on total daily intakes, all bandwidths. 14

Table C9. Model (10): Impact at cut-off 11, all bandwidths. 15

Table D1. Impact on daily intakes for children taking the morning snack, all outcomes and all bandwidths.

Table D2. Impact on intakes from all meals except the morning snack, for children taking the morning snack, all outcomes and all bandwidths. 16

Table D3. Impact on intakes from the afternoon snack for children taking both the morning and afternoon snack, all outcomes and all bandwidths. 16

Table D4. Impact on daily intakes for children taking both the morning snack and the afternoon snack, all outcomes and all bandwidths.

Table D5. Impact on intakes from all meals except the snacks (morning and afternoon), for children taking both the morning and the afternoon snack, all outcomes and all bandwidths.

Table D6. Impact on intakes from the afternoon snack for children taking the afternoon snack only, all outcomes and all bandwidths.

Table D7. Impact on daily intakes for children taking the afternoon snack only, all outcomes and all bandwidths.

Table D8. Impact on intakes from all meals except the afternoon snack, for children taking the afternoon snack only, all outcomes and all bandwidths. 


\section{A FIRST STAGE ESTIMATES}

Table A1. First stage estimates: OLS versus Logit results, cut-off 12, all bandwidths.

\begin{tabular}{|c|c|c|c|c|c|c|c|c|}
\hline & \multicolumn{4}{|c|}{ OLS estimates } & \multicolumn{4}{|c|}{ Logit estimates } \\
\hline & Bdwth 6-18 & Bdwth 7-17 & Bdwth 8-16 & Bdwth 9-15 & Bdwth 6-18 & Bdwth 7-17 & Bdwth 8-16 & Bdwth 9-15 \\
\hline \multirow[t]{2}{*}{$I($ Age $\geq 12)$} & $0.719 * * *$ & $0.735 * * *$ & $0.616^{* * *}$ & $0.500 * * *$ & $3.564 * * *$ & $3.764 * * *$ & $2.518 * * *$ & $1.163 * *$ \\
\hline & -0.038 & -0.04 & -0.041 & -0.046 & -0.383 & -0.404 & -0.446 & -0.543 \\
\hline \multirow[t]{2}{*}{ Age - 12} & $0.011 * *$ & 0.006 & $0.036 * * *$ & $0.072 * * *$ & $0.123 * *$ & 0.064 & $0.506 * * *$ & $1.374 * * *$ \\
\hline & -0.005 & -0.006 & -0.008 & -0.011 & -0.058 & -0.065 & -0.11 & -0.226 \\
\hline \multirow[t]{2}{*}{ Constant } & $0.156^{* * *}$ & $0.158 * * *$ & $0.254 * * *$ & $0.353 * * *$ & $-1.611 * * *$ & $-1.633 * * *$ & $-0.498 *$ & $0.993 * * *$ \\
\hline & -0.023 & -0.024 & -0.025 & -0.028 & -0.231 & -0.234 & -0.268 & -0.368 \\
\hline Observations & 1,070 & 981 & 794 & 617 & 1,070 & 981 & 794 & 617 \\
\hline R-squared & 0.618 & 0.586 & 0.639 & 0.642 & - & - & - & - \\
\hline Pseudo R-squared & - & - & - & - & 0.513 & 0.482 & 0.559 & 0.616 \\
\hline
\end{tabular}

Notes: The table shows coefficients and robust standard errors (in parentheses) of the first stage model (equation 1 in the text) estimated both with Ordinary Least Squares and as a Logit model on four different bandwidths. The model estimates the jump in the probability of attending secondary school at the cut-off age of 12 years old. $I$ (Age $\geq 12)$ is the binary indicator taking on the value of 1 when the subject is 12 years old or older and 0 otherwise.

Significance: $* \mathrm{p}<0.1 ; * * \mathrm{p}<0.05 ; * * * \mathrm{p}<0.01$ 
Table A2. Second stage estimates: Baseline model using Logit models at the first stage, cut-off 12, all bandwidths.

\begin{tabular}{lrrrr}
\hline & \multicolumn{4}{c}{ Bandwidth } \\
Outcome & \multicolumn{1}{c}{$6-18$} & $7-17$ & \multicolumn{1}{c}{$8-16$} & \multicolumn{1}{c}{$9-15$} \\
\hline \multirow{2}{*}{ Energy intake (Kcal) } & -22.182 & -9.638 & -14.069 & -40.029 \\
& $(31.722)$ & $(32.738)$ & $(38.262)$ & $(39.701)$ \\
Sugar intake (g) & $-9.546^{* *}$ & $-11.643 * * *$ & $-11.182 * *$ & $-10.001 *$ \\
& $(3.993)$ & $(4.463)$ & $(5.130)$ & $(5.755)$ \\
Fat intake (g) & -0.757 & 0.175 & 0.025 & -1.509 \\
& $(1.901)$ & $(1.718)$ & $(2.085)$ & $(2.044)$ \\
Saturated fat intake $(\mathrm{g})$ & -0.243 & 0.134 & -0.062 & -0.715 \\
& $(0.909)$ & $(0.938)$ & $(1.152)$ & $(1.025)$ \\
$\mathrm{N}$ & 484 & 413 & 299 & 216 \\
& & & & \\
Morning snack frequency & $-0.257 * * *$ & $-0.229 * * *$ & $-0.316 * * *$ & $-0.682 * * *$ \\
& $(0.077)$ & $(0.077)$ & $(0.104)$ & $(0.223)$ \\
$\mathrm{N}$ & 1,517 & 1,361 & 1,111 & 884 \\
\hline
\end{tabular}

Notes: Robust standard errors in parentheses. Significance: $* \mathrm{p}<0.1 ; * * \mathrm{p}<0.05$; $* * * \mathrm{p}<0.01$. 


\section{B SECOND STAGE ESTIMATES}

Table B1. Second stage estimates, bandwidth 6-18, full results.

\begin{tabular}{|c|c|c|c|c|c|}
\hline & $\begin{array}{l}\text { Energy intake } \\
\text { (Kcal) }\end{array}$ & $\begin{array}{c}\text { Sugar } \\
\text { intake }(\mathrm{g})\end{array}$ & $\begin{array}{l}\text { Fat intake } \\
(\mathrm{g})\end{array}$ & $\begin{array}{l}\text { Saturated fat } \\
\text { intake }(\mathrm{g})\end{array}$ & $\begin{array}{l}\text { Morning snack } \\
\text { frequency }\end{array}$ \\
\hline \multirow[t]{2}{*}{ Policy } & -24.050 & -0.204 & -1.032 & -0.513 & $0.206^{* * *}$ \\
\hline & $(15.585)$ & (1.739) & $(0.821)$ & $(0.433)$ & $(0.045)$ \\
\hline \multirow[t]{2}{*}{$\hat{W}$} & 3.261 & $8.309 *$ & -0.921 & -0.262 & $0.255^{* * *}$ \\
\hline & $(41.066)$ & (4.939) & $(2.040)$ & (1.087) & $(0.057)$ \\
\hline \multirow[t]{2}{*}{$\hat{W} \times$ Policy } & -22.201 & $-9.544 * *$ & -0.763 & -0.244 & $-0.257 * * *$ \\
\hline & (31.814) & $(4.000)$ & (1.910) & $(0.911)$ & $(0.077)$ \\
\hline \multirow[t]{2}{*}{ Age -12} & 3.261 & -0.071 & 0.278 & 0.086 & $-0.077 * * *$ \\
\hline & $(4.255)$ & $(0.399)$ & $(0.235)$ & $(0.115)$ & $(0.009)$ \\
\hline Treat $\times$ Age & - & - & - & - & $\begin{array}{r}0.067 * * * \\
(0.009)\end{array}$ \\
\hline \multirow[t]{2}{*}{ Policy $\times$ Age } & - & - & - & - & $0.028 * * *$ \\
\hline & & & & & $(0.010)$ \\
\hline Policy $\times$ Treat $\times$ Age & - & - & - & - & - \\
\hline \multirow[t]{2}{*}{ Constant } & $191.432 * * *$ & $14.657 * * *$ & $7.936 * * *$ & $3.744 * * *$ & $-0.106 * * *$ \\
\hline & (25.852) & $(2.660)$ & (1.379) & (0.704) & $(0.037)$ \\
\hline $\mathrm{N}$ & 484 & 484 & 484 & 484 & 1517 \\
\hline
\end{tabular}

Notes: The table shows full results of the estimation of the second stage outcome equation (equation 3 in the text) on the 6-18 bandwidth using 12 years old as cut-off point. Policy is a binary variable taking on the value 1 if the subject belongs to the INCA2 sample and 0 otherwise. Wis the estimated probability of attending secondary school (from the first stage). Treat is a binary variable taking on the value of 1 if the subject is 12 years old or older. Treat $\times$ Age, Policy $\times$ Age and Policy $\times$ Treat $\times$ Age are interaction terms. The inclusion of the interaction terms that allow the trend to change between the two groups and before and after the policy comes at the cost of reduced efficiency due to some collinearity. Thus, nonsignificant interaction terms have been dropped in a backward selection process. Robust standard error in parentheses.

Significance: $* \mathrm{p}<0.1 ; * * \mathrm{p}<0.05 ; * * * \mathrm{p}<0.01$. 
Table B2. Second stage estimates, bandwidth 7-17, full results.

\begin{tabular}{|c|c|c|c|c|c|}
\hline & $\begin{array}{l}\text { Energy } \\
\text { intake } \\
\text { (Kcal) }\end{array}$ & $\begin{array}{c}\text { Sugar intake } \\
(\mathrm{g})\end{array}$ & $\begin{array}{l}\text { Fat intake } \\
\quad(\mathrm{g})\end{array}$ & $\begin{array}{l}\text { Saturated fat } \\
\text { intake }(\mathrm{g})\end{array}$ & $\begin{array}{l}\text { Morning } \\
\text { snack } \\
\text { frequency }\end{array}$ \\
\hline \multirow[t]{2}{*}{ Policy } & -20.114 & 1.059 & -0.691 & -0.408 & $0.200 * * *$ \\
\hline & $(19.415)$ & $(2.198)$ & $(1.029)$ & $(0.550)$ & $(0.045)$ \\
\hline \multirow[t]{2}{*}{$\hat{W}$} & 4.211 & $9.169 *$ & -0.850 & -0.267 & $0.247 * * *$ \\
\hline & $(43.745)$ & $(5.203)$ & $(2.176)$ & (1.164) & $(0.057)$ \\
\hline \multirow[t]{2}{*}{$\hat{W} \times$ Policy } & -9.536 & $-11.657 * * *$ & 0.183 & 0.137 & $-0.228 * * *$ \\
\hline & $(32.776)$ & (4.474) & $(1.720)$ & $(0.939)$ & (0.077) \\
\hline \multirow[t]{2}{*}{ Age -12} & 1.626 & 0.04 & 0.157 & 0.042 & $-0.076 * * *$ \\
\hline & (4.658) & $(0.457)$ & $(0.229)$ & $(0.127)$ & $(0.011)$ \\
\hline \multirow[t]{2}{*}{ Treat $\times$ Age } & - & - & - & - & $0.072 * * *$ \\
\hline & & & & & $(0.012)$ \\
\hline \multirow[t]{2}{*}{ Policy $\times$ Age } & - & - & - & - & $0.021 * *$ \\
\hline & & & & & $(0.011)$ \\
\hline Policy $\times$ Treat $\times$ Age & - & - & - & - & - \\
\hline \multirow[t]{2}{*}{ Constant } & $182.670 * * *$ & $14.109 * * *$ & $7.229 * * *$ & $3.515 * * *$ & $-0.113 * * *$ \\
\hline & $(27.524)$ & (2.946) & (1.391) & $(0.755)$ & $(0.038)$ \\
\hline $\mathrm{N}$ & 413 & 413 & 413 & 413 & 1361 \\
\hline
\end{tabular}

Notes: The table shows full results of the estimation of the second stage outcome equation (equation 3 in the text) on the 7-17 bandwidth using 12 years old as cut-off point. The inclusion of the interaction terms that allow the trend to change between the two groups and before and after the policy comes at the cost of reduced efficiency due to some collinearity. Thus, non-significant interaction terms have been dropped in a backward selection process. Robust standard error in parentheses.

Significance: $* \mathrm{p}<0.1 ; * * \mathrm{p}<0.05 ; * * * \mathrm{p}<0.01$. 
Table B3. Second stage estimates, bandwidth 8-16, full results.

\begin{tabular}{|c|c|c|c|c|c|}
\hline & $\begin{array}{l}\text { Energy } \\
\text { intake } \\
\text { (Kcal) }\end{array}$ & $\begin{array}{l}\text { Sugar intake } \\
(\mathrm{g})\end{array}$ & $\begin{array}{l}\text { Fat intake } \\
\quad(\mathrm{g})\end{array}$ & $\begin{array}{l}\text { Saturated fat } \\
\text { intake }(\mathrm{g})\end{array}$ & $\begin{array}{l}\text { Morning } \\
\text { snack } \\
\text { frequency }\end{array}$ \\
\hline \multirow[t]{2}{*}{ Policy } & -25.241 & -0.111 & -0.844 & -0.407 & $0.251 * * *$ \\
\hline & (25.679) & $(2.935)$ & (1.404) & $(0.743)$ & (0.063) \\
\hline \multirow[t]{2}{*}{$\hat{W}$} & 23.265 & 8.502 & 0.039 & 0.246 & $0.299 * * *$ \\
\hline & $(63.709)$ & $(6.824)$ & $(3.265)$ & $(1.800)$ & $(0.076)$ \\
\hline \multirow[t]{2}{*}{$\hat{W} \times$ Policy } & -13.609 & $-11.559 * *$ & 0.142 & -0.027 & $-0.324 * * *$ \\
\hline & $(38.951)$ & (5.307) & $(2.139)$ & $(1.185)$ & $(0.103)$ \\
\hline \multirow[t]{2}{*}{ Age -12} & -2.113 & 0.135 & -0.038 & -0.046 & $-0.080 * * *$ \\
\hline & $(9.437)$ & $(0.915)$ & $(0.496)$ & $(0.286)$ & $(0.016)$ \\
\hline Treat $\times$ Age & - & - & - & - & $\begin{array}{r}0.048 * * * \\
(0.015)\end{array}$ \\
\hline Policy $\times$ Age & - & - & - & - & $\begin{array}{r}0.046^{* * * *} \\
(0.017)\end{array}$ \\
\hline Policy $\times$ Treat $\times$ Age & - & - & 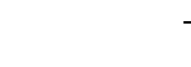 & - & \\
\hline \multirow[t]{2}{*}{ Constant } & $176.428 * * *$ & $15.298 * * *$ & $6.830 * * *$ & $3.266 * * *$ & $-0.125 * *$ \\
\hline & (43.109) & $(4.446)$ & $(2.255)$ & (1.259) & $(0.050)$ \\
\hline $\mathrm{N}$ & 299 & 299 & 299 & 299 & 1111 \\
\hline
\end{tabular}

Notes: The table shows full results of the estimation of the second stage outcome equation (equation 3 in the text) on the 8-16 bandwidth using 12 years old as cut-off point. The inclusion of the interaction terms that allow the trend to change between the two groups and before and after the policy comes at the cost of reduced efficiency due to some collinearity. Thus, non-significant interaction terms have been dropped in a backward selection process. Robust standard error in parentheses.

Significance: $* \mathrm{p}<0.1 ; * * \mathrm{p}<0.05 ; * * * \mathrm{p}<0.01$. 
Table B4. Second stage estimates, bandwidth 9-15, full results.

\begin{tabular}{|c|c|c|c|c|c|}
\hline & $\begin{array}{l}\text { Energy } \\
\text { intake } \\
\text { (Kcal) }\end{array}$ & $\begin{array}{l}\text { Sugar intake } \\
(\mathrm{g})\end{array}$ & $\begin{array}{l}\text { Fat intake } \\
(\mathrm{g})\end{array}$ & $\begin{array}{l}\text { Saturated fat } \\
\text { intake }(\mathrm{g})\end{array}$ & $\begin{array}{l}\text { Morning } \\
\text { snack } \\
\text { frequency }\end{array}$ \\
\hline \multirow[t]{2}{*}{ Policy } & 22.482 & 1.683 & 1.596 & 0.978 & $0.291 * * *$ \\
\hline & $(29.727)$ & $(3.993)$ & $(1.546)$ & $(0.733)$ & $(0.092)$ \\
\hline \multirow[t]{2}{*}{$\hat{W}$} & $187.051 * *$ & $20.352 * *$ & $8.567 *$ & $5.225^{* *}$ & $0.307 * * *$ \\
\hline & (92.778) & (9.287) & $(4.462)$ & $(2.399)$ & $(0.105)$ \\
\hline \multirow[t]{2}{*}{$\hat{W} \times$ Policy } & -58.199 & $-10.448^{*}$ & -2.210 & -1.178 & $-0.374 * * *$ \\
\hline & $(40.684)$ & (6.017) & $(2.102)$ & $(1.014)$ & $(0.143)$ \\
\hline \multirow[t]{2}{*}{ Age -12} & $-33.272 *$ & $-2.894 *$ & $-1.650 * *$ & $-1.010 * *$ & $-0.066 * * *$ \\
\hline & $(17.067)$ & $(1.563)$ & $(0.822)$ & $(0.451)$ & $(0.022)$ \\
\hline Treat $\times$ Age & - & - & - & - & - \\
\hline \multirow[t]{2}{*}{ Policy $\times$ Age } & - & - & - & - & $0.062 * *$ \\
\hline & & & & & 0.028 \\
\hline Policy $\times$ Treat $\times$ Age & - & - & - & - & - \\
\hline \multirow[t]{2}{*}{ Constant } & 46.894 & 5.243 & 0.093 & -0.789 & -0.103 \\
\hline & $(64.987)$ & $(6.452)$ & $(3.151)$ & $(1.681)$ & $(0.066)$ \\
\hline $\mathrm{N}$ & 216 & 216 & 216 & 216 & 884 \\
\hline
\end{tabular}

Notes: The table shows full results of the estimation of the second stage outcome equation (equation 3 in the text) on the 9-15 bandwidth using 12 years old as cut-off point. The inclusion of the interaction terms that allow the trend to change between the two groups and before and after the policy comes at the cost of reduced efficiency due to some collinearity. Thus, non-significant interaction terms have been dropped in a backward selection process. Robust standard error in parentheses.

Significance: $* \mathrm{p}<0.1 ; * * \mathrm{p}<0.05 ; * * * \mathrm{p}<0.01$. 


\section{VALIDATION CHECKS}

\section{Robustness to Model Specification}

Table C1. Model (2): Kernel-weighted local polynomial regression, all bandwidths.

\begin{tabular}{lrrrr}
\hline & \multicolumn{4}{c}{ Bandwidth } \\
Outcome & $6-18$ & \multicolumn{1}{c}{$7-17$} & \multicolumn{1}{c}{$8-16$} & \multicolumn{1}{c}{$9-15$} \\
\hline \multirow{2}{*}{ Energy intake (Kcal) } & & & & \\
& -18.945 & -6.018 & -15.933 & -45.500 \\
Sugar intake $(\mathrm{g})$ & $(32.785)$ & $(33.297)$ & $(39.375)$ & $(44.652)$ \\
& $-8.957 * *$ & $-11.203 * *$ & $-11.890 * *$ & -9.437 \\
Fat intake $(\mathrm{g})$ & $(4.122)$ & $(4.610)$ & $(5.467)$ & $(6.344)$ \\
& -0.874 & 0.120 & -0.227 & -1.723 \\
Saturated fat intake $(\mathrm{g})$ & $(1.975)$ & $(1.748)$ & $(2.158)$ & $(2.294)$ \\
& -0.322 & 0.045 & -0.309 & -0.837 \\
$\mathrm{~N}$ & $(0.959)$ & $(0.967)$ & $(1.181)$ & $(1.123)$ \\
& 484 & 413 & 299 & 216 \\
Morning snack frequency & & & & \\
& $-0.229 * * *$ & $-0.190 * *$ & $-0.290 * * *$ & $-0.365 * *$ \\
$\mathrm{~N}$ & $(0.076)$ & $(0.076)$ & $(0.102)$ & $(0.145)$ \\
\hline
\end{tabular}

Notes: Robust standard errors in parentheses.

Significance: $* \mathrm{p}<0.1 ; * * \mathrm{p}<0.05 ; * * * \mathrm{p}<0.01$. 
Table C2. Model (3): Baseline model with gender, height, weight, household size as additional covariates, all bandwidths.

\begin{tabular}{lrrrr}
\hline & \multicolumn{4}{c}{ Bandwidth } \\
Outcome & $6-18$ & $7-17$ & \multicolumn{1}{c}{$8-16$} & \multicolumn{1}{c}{$9-15$} \\
\hline \multirow{2}{*}{ Energy intake (Kcal) } & -20.751 & -12.397 & $\mathbf{- 1 8 . 8 4 8}$ & -46.302 \\
& $(32.131)$ & $(32.681)$ & $\mathbf{( 3 9 . 3 0 7 )}$ & $(41.575)$ \\
Sugar intake (g) & $-9.317 * *$ & $-11.727 * *$ & $-11.233^{* *}$ & $\mathbf{- 1 0 . 0 9 3} *$ \\
& $(4.074)$ & $(4.561)$ & $(5.544)$ & $\mathbf{( 6 . 1 0 3 )}$ \\
Fat intake (g) & -0.647 & 0.167 & $\mathbf{0 . 0 3 1}$ & -1.380 \\
& $(1.932)$ & $(1.697)$ & $\mathbf{( 2 . 1 2 8})$ & $(2.151)$ \\
Saturated fat intake (g) & -0.215 & 0.122 & $\mathbf{- 0 . 1 5 2}$ & -0.781 \\
& $(0.915)$ & $(0.930)$ & $\mathbf{( 1 . 1 8 3 )}$ & $(1.041)$ \\
N & 466 & 399 & 292 & 212 \\
& & & & \\
Morning snack frequency & $-0.267 * * *$ & $\mathbf{- 0 . 2 4 9} * * *$ & $-0.349 * * *$ & $-0.392 * * *$ \\
& $(0.079)$ & $\mathbf{( 0 . 0 7 9 )}$ & $(0.104)$ & $(0.146)$ \\
N & 1,455 & 1,305 & 1,070 & 854 \\
\hline
\end{tabular}

Notes: Robust standard errors in parentheses.

Significance: $* \mathrm{p}<0.1$; ** $\mathrm{p}<0.05$; $* * * \mathrm{p}<0.01$.

Optimal bandwidths in bold. 
Table C3. Model (4): Sharp differenced regression discontinuity design, all bandwidths.

\begin{tabular}{lrrrr}
\hline & \multicolumn{4}{c}{ Bandwidth } \\
Outcome & \multicolumn{1}{c}{$6-18$} & $7-17$ & \multicolumn{1}{c}{$8-16$} & \multicolumn{1}{c}{$9-15$} \\
\hline \multirow{2}{*}{ Energy intake (Kcal) } & -16.911 & -7.452 & $\mathbf{- 9 . 6 1 3}$ & -39.194 \\
& $(25.085)$ & $(25.313)$ & $\mathbf{( 3 0 . 5 9 7 )}$ & $(33.036)$ \\
Sugar intake (g) & $-7.663^{* *}$ & $-8.961 * * *$ & $-8.829 * *$ & $\mathbf{- 8 . 4 8 3 *}$ \\
& $(3.181)$ & $(3.442)$ & $(4.078)$ & $\mathbf{( 4 . 5 7 1 )}$ \\
Fat intake (g) & -0.539 & 0.140 & $\mathbf{0 . 1 4 8}$ & -1.442 \\
& $(1.478)$ & $(1.325)$ & $\mathbf{( 1 . 6 3 8 )}$ & $(1.666)$ \\
Saturated fat intake (g) & -0.165 & 0.107 & $\mathbf{0 . 0 3 0}$ & -0.777 \\
& $(0.714)$ & $(0.722)$ & $\mathbf{( 0 . 8 9 2})$ & $(0.818)$ \\
N & 484 & 413 & 299 & 216 \\
& & & & \\
Morning snack frequency & $-0.185^{* * *}$ & $\mathbf{- 0 . 1 6 7 * * *}$ & $-0.200 * * *$ & $-0.189 * * *$ \\
& $(0.055)$ & $(\mathbf{0 . 0 5 7})$ & $(0.063)$ & $(0.071)$ \\
$\mathrm{N}$ & 1,517 & 1,361 & 1,111 & 884 \\
\hline
\end{tabular}

Notes: Robust standard errors in parentheses.

Significance: $* \mathrm{p}<0.1 ; * * \mathrm{p}<0.05 ; * * * \mathrm{p}<0.01$.

Optimal bandwidths in bold. 


\section{Impact on Different Meal Occasions}

Table C4. Model (5): Impact on total morning and afternoon snack intakes, all bandwidths.

\begin{tabular}{lrrrr}
\hline & \multicolumn{4}{c}{ Bandwidth } \\
Outcome & \multicolumn{1}{c}{$6-18$} & \multicolumn{1}{c}{$7-17$} & \multicolumn{1}{c}{$8-16$} & \multicolumn{1}{c}{$9-15$} \\
\hline Energy intake (Kcal) & -8.946 & -5.236 & -7.847 & $\mathbf{- 4 5 . 9 3 4}$ \\
& $(33.639)$ & $(36.316)$ & $(40.198)$ & $\mathbf{( 4 5 . 8 7 0 )}$ \\
Sugar intake $(\mathrm{g})$ & $-7.859 * *$ & $\mathbf{- 9 . 2 7 1} * * *$ & $-8.941 * *$ & $-12.081^{* *}$ \\
& $(3.297)$ & $\mathbf{( 3 . 5 8 7 )}$ & $(4.154)$ & $(4.784)$ \\
Fat intake $(\mathrm{g})$ & 0.265 & 0.485 & 0.361 & $\mathbf{- 1 . 0 6 0}$ \\
& $(1.582)$ & $(1.690)$ & $(1.790)$ & $\mathbf{( 2 . 0 7 1 )}$ \\
Saturated fat intake $(\mathrm{g})$ & 0.014 & -2.758 & -3.824 & $\mathbf{- 0 . 7 9 5}$ \\
& $(0.791)$ & $(1.849)$ & $(2.415)$ & $\mathbf{( 0 . 9 9 4 )}$ \\
$\mathrm{N}$ & 1,304 & 1,169 & 955 & 760 \\
& & & & \\
Morning snack frequency & $-0.257 * * *$ & $-0.228 * * *$ & $-0.324 * * *$ & $\mathbf{- 0 . 3 7 4} * * *$ \\
& $(0.077)$ & $(0.077)$ & $(0.103)$ & $\mathbf{( 0 . 1 4 3 )}$ \\
$\mathrm{N}$ & 1,517 & 1,361 & 1,111 & 760 \\
\hline Notes: Robust standard errors in parentheses & & &
\end{tabular}

Notes: Robust standard errors in parentheses.

Significance: $* \mathrm{p}<0.1 ; * * \mathrm{p}<0.05 ; * * * \mathrm{p}<0.01$.

Optimal bandwidths in bold. 
Table C5. Model (6): Impact on afternoon snack intakes (the sample excludes children with zero calories from the afternoon snack), all bandwidths.

\begin{tabular}{|c|c|c|c|c|}
\hline \multirow[b]{2}{*}{ Outcome } & \multicolumn{4}{|c|}{ Bandwidth } \\
\hline & $6-18$ & $7-17$ & $8-16$ & $9-15$ \\
\hline \multirow[t]{2}{*}{ Energy intake (Kcal) } & -6.220 & -2.877 & -7.648 & -29.639 \\
\hline & $(32.906)$ & $(35.565)$ & $(38.701)$ & (44.556) \\
\hline \multirow[t]{2}{*}{ Sugar intake $(\mathrm{g})$} & $-6.668 * *$ & -5.647 & -5.849 & -6.178 \\
\hline & $(3.181)$ & (3.455) & $(3.834)$ & $(4.702)$ \\
\hline \multirow[t]{2}{*}{ Fat intake $(\mathrm{g})$} & 0.010 & -2.541 & -4.505 & -1.309 \\
\hline & $(1.490)$ & $(2.444)$ & $(2.793)$ & (1.952) \\
\hline \multirow[t]{2}{*}{ Saturated fat intake $(\mathrm{g})$} & -0.376 & -1.661 & $-2.877^{*}$ & -0.774 \\
\hline & $(0.767)$ & $(1.331)$ & $(1.523)$ & $(0.963)$ \\
\hline $\mathrm{N}$ & 1,295 & 1,161 & 952 & 758 \\
\hline \multirow[t]{2}{*}{ Morning snack frequency } & 0.018 & -0.168 & -0.022 & -0.032 \\
\hline & $(0.049)$ & $(\mathbf{0 . 1 1 3})$ & $(0.060)$ & $(0.069)$ \\
\hline $\mathrm{N}$ & 1,517 & 1,361 & 1,111 & 884 \\
\hline
\end{tabular}

Significance: $* \mathrm{p}<0.1 ; * * \mathrm{p}<0.05 ; * * * \mathrm{p}<0.01$.

Optimal bandwidths in bold.

Table C6. Model (7): Impact on lunch intakes, all bandwidths.

\begin{tabular}{lrrrr}
\hline & \multicolumn{4}{c}{ Bandwidth } \\
Outcome & \multicolumn{1}{c}{$6-18$} & \multicolumn{1}{c}{$7-17$} & \multicolumn{1}{c}{$8-16$} & \multicolumn{1}{c}{$9-15$} \\
\hline Energy intake (Kcal) & -5.514 & -8.742 & -24.568 & $\mathbf{- 4 3 . 6 2 2}$ \\
Sugar intake $(\mathrm{g})$ & $(32.388)$ & $(36.130)$ & $(40.764)$ & $\mathbf{( 4 5 . 9 0 2 )}$ \\
& 1.990 & $\mathbf{2 . 1 0 3}$ & 1.935 & 0.020 \\
Fat intake $(\mathrm{g})$ & $(1.899)$ & $\mathbf{( 2 . 1 1 1 )}$ & $(2.264)$ & $(2.557)$ \\
& -1.799 & -1.774 & -1.020 & $\mathbf{- 1 . 4 0 0}$ \\
Saturated fat intake $(\mathrm{g})$ & $(1.805)$ & $(2.048)$ & $(2.227)$ & $\mathbf{( 2 . 4 7 8 )}$ \\
& -0.842 & -0.512 & -0.821 & $\mathbf{- 0 . 8 8 1}$ \\
$\mathrm{N}$ & $(0.802)$ & $(0.874)$ & $(1.017)$ & $\mathbf{( 1 . 1 0 7 )}$ \\
\hline Notes: Robust standard errors in parentheses. & & & 880 \\
\hline
\end{tabular}

Significance: $* \mathrm{p}<0.1$; ** $\mathrm{p}<0.05$; *** $\mathrm{p}<0.01$.

Optimal bandwidths in bold. 
Table C7. Model (8): Impact on dinner intakes, all bandwidths.

\begin{tabular}{lrrrr}
\hline \multirow{2}{*}{ Outcome } & \multicolumn{4}{c}{ Bandwidth } \\
\hline Energy intake (Kcal) & \multicolumn{1}{c}{$6-18$} & \multicolumn{1}{c}{$7-17$} & \multicolumn{1}{c}{$8-16$} & \multicolumn{1}{c}{$9-15$} \\
& -29.114 & $\mathbf{- 2 3 . 1 8 2}$ & -67.160 & -77.551 \\
Sugar intake $(\mathrm{g})$ & $(34.810)$ & $\mathbf{( 3 8 . 2 1 3})$ & $(41.808)$ & $(48.517)$ \\
& -2.262 & $\mathbf{- 1 . 1 2 6}$ & -2.630 & $-4.929 *$ \\
Fat intake (g) & $(2.294)$ & $\mathbf{( 2 . 5 0 9 )}$ & $(2.781)$ & $(2.943)$ \\
& -1.881 & -1.710 & -3.496 & $\mathbf{- 2 . 3 9 3}$ \\
Saturated fat intake $(\mathrm{g})$ & $(1.808)$ & $(1.977)$ & $(2.143)$ & $\mathbf{( 2 . 5 1 5 )}$ \\
& -1.082 & -1.305 & $-2.087 * *$ & $\mathbf{- 1 . 6 2 9}$ \\
$\mathrm{N}$ & $(0.830)$ & $(0.913)$ & $(0.976)$ & $\mathbf{( 1 . 1 2 7})$ \\
\hline
\end{tabular}

Notes: Robust standard errors in parentheses.

Significance: $* \mathrm{p}<0.1$; ** $\mathrm{p}<0.05$; *** $\mathrm{p}<0.01$.

Optimal bandwidths in bold.

Table C8. Model (9): Impact on total daily intakes, all bandwidths.

\begin{tabular}{lrrrr}
\hline & \multicolumn{4}{c}{ Bandwidth } \\
Outcome & \multicolumn{1}{c}{$6-18$} & \multicolumn{1}{c}{$7-17$} & \multicolumn{1}{c}{$8-16$} & \multicolumn{1}{c}{$9-15$} \\
\hline Energy intake (Kcal) & 18.800 & $\mathbf{- 1 3 . 1 7 5}$ & -74.771 & -147.766 \\
Sugar intake $(\mathrm{g})$ & $(79.506)$ & $\mathbf{( 8 8 . 5 7 9})$ & $(98.117)$ & $(113.134)$ \\
& 0.319 & $\mathbf{0 . 4 8 9}$ & -1.105 & -4.222 \\
Fat intake (g) & $(5.919)$ & $\mathbf{( 6 . 5 5 8 )}$ & $(7.258)$ & $(7.982)$ \\
& -3.201 & -2.698 & -4.426 & $\mathbf{- 6 . 7 0 2}$ \\
Saturated fat intake $(\mathrm{g})$ & $(3.499)$ & $(3.896)$ & $(4.305)$ & $\mathbf{( 4 . 8 8 1 )}$ \\
& -1.684 & -1.743 & -2.686 & $\mathbf{- 3 . 8 0 1}$ \\
$\mathrm{N}$ & $(1.658)$ & $(1.838)$ & $(2.017)$ & $\mathbf{( 2 . 2 7 2})$ \\
\hline
\end{tabular}

Notes: Robust standard errors in parentheses.

Significance: $* \mathrm{p}<0.1 ; * * \mathrm{p}<0.05 ; * * * \mathrm{p}<0.01$.

Optimal bandwidths in bold. 


\section{Impact at Different Cut-Off Ages}

Table C9. Model (10): Impact at cut-off 11, all bandwidths.

\begin{tabular}{lrrr}
\hline & \multicolumn{3}{c}{ Bandwidth } \\
Outcome & \multicolumn{1}{c}{$6-16$} & \multicolumn{1}{c}{75} & \multicolumn{1}{c}{$8-14$} \\
\hline Energy intake (Kcal) & -17.287 & -22.180 & $\mathbf{- 1 6 . 9 7 9}$ \\
& $(27.649)$ & $(29.583)$ & $\mathbf{( 3 5 . 3 8 6 )}$ \\
Sugar intake (g) & $-10.215^{* *}$ & $\mathbf{- 9 . 5 4 3 * *}$ & -7.472 \\
& $(3.993)$ & $\mathbf{( 4 . 0 8 7 )}$ & $(4.808)$ \\
Fat intake (g) & 0.098 & -0.430 & $\mathbf{- 0 . 5 7 4}$ \\
& $(1.492)$ & $(1.522)$ & $\mathbf{( 1 . 8 9 3 )}$ \\
Saturated fat intake $(\mathrm{g})$ & -0.059 & -0.073 & $\mathbf{- 0 . 1 9 2}$ \\
& $(0.823)$ & $(0.791)$ & $\mathbf{( 0 . 9 7 2})$ \\
$\mathrm{N}$ & 416 & 318 & 236 \\
& & & \\
Morning snack frequency & -0.012 & $-0.078 *$ & $\mathbf{- 0 . 0 3 7}$ \\
& $(0.043)$ & $(0.045)$ & $\mathbf{( 0 . 0 4 8})$ \\
$\mathrm{N}$ & 1,333 & 1,099 & 875 \\
\hline Notes: & Robust standard errors in parentheses. & &
\end{tabular}

Significance: $* \mathrm{p}<0.1 ; * * \mathrm{p}<0.05 ; * * * \mathrm{p}<0.01$.

Optimal bandwidths in bold.

\section{COMPENSATION EFFECTS}

Table D1. Impact on daily intakes for children taking the morning snack, all outcomes and all bandwidths.

\begin{tabular}{lrrrr}
\hline & \multicolumn{4}{c}{ Bandwidth } \\
Outcome & \multicolumn{1}{c}{$6-18$} & $7-17$ & \multicolumn{1}{c}{$8-16$} & \multicolumn{1}{c}{$9-15$} \\
\hline Energy intake (Kcal) & 46.376 & $\mathbf{2 7 . 3 7 0}$ & 46.051 & -35.708 \\
& $(185.188)$ & $\mathbf{( 1 8 6 . 6 6 9 )}$ & $(207.100)$ & $(257.922)$ \\
Sugar intake (g) & 12.600 & 14.785 & $\mathbf{1 7 . 3 6 3}$ & 18.840 \\
& $(12.323)$ & $(14.130)$ & $\mathbf{( 1 7 . 0 3 0 )}$ & $(20.414)$ \\
Fat intake (g) & -1.752 & $\mathbf{8 . 5 5 8}$ & 3.515 & 3.848 \\
& $(9.101)$ & $\mathbf{( 8 . 8 3 4 )}$ & $(10.252)$ & $(11.561)$ \\
Saturated fat intake $(\mathrm{g})$ & -0.001 & 2.644 & 1.154 & $\mathbf{2 . 4 7 1}$ \\
& $(4.781)$ & $(4.340)$ & $(5.030)$ & $\mathbf{( 5 . 6 9 5 )}$ \\
$\mathrm{N}$ & 484 & 413 & 299 & 216 \\
\hline Notes: Robust standard errors in parentheses. & & &
\end{tabular}

Significance: $* \mathrm{p}<0.1$; ** $\mathrm{p}<0.05 ; * * * \mathrm{p}<0.01$.

Optimal bandwidths in bold. 
Table D2. Impact on intakes from all meals except the morning snack, for children taking the morning snack, all outcomes and all bandwidths.

\begin{tabular}{lrrrr}
\hline & \multicolumn{4}{c}{ Bandwidth } \\
Outcome & \multicolumn{1}{c}{$6-18$} & \multicolumn{1}{c}{$7-17$} & \multicolumn{1}{c}{$8-16$} & \multicolumn{1}{c}{$9-15$} \\
\hline Energy intake (Kcal) & 101.907 & $\mathbf{3 3 . 6 3 7}$ & 53.541 & 16.861 \\
& $(164.798)$ & $\mathbf{( 1 7 7 . 9 8 8})$ & $(197.558)$ & $(247.580)$ \\
Sugar intake $(\mathrm{g})$ & $22.827^{* *}$ & $26.236^{* *}$ & $\mathbf{2 8 . 7 9 8 *}$ & 29.184 \\
& $(11.138)$ & $(12.688)$ & $\mathbf{( 1 4 . 8 9 3 )}$ & $(18.145)$ \\
Fat intake $(\mathrm{g})$ & 0.532 & $\mathbf{3 . 4 3 7}$ & 2.982 & 5.668 \\
& $(7.643)$ & $\mathbf{( 8 . 3 8 2}$ & $(9.785)$ & $(11.225)$ \\
Saturated fat intake $(\mathrm{g})$ & 1.404 & 2.559 & 1.343 & $\mathbf{3 . 0 3 1}$ \\
& $(3.845)$ & $(4.155)$ & $(4.824)$ & $\mathbf{( 5 . 5 6 1 )}$ \\
$\mathrm{N}$ & 484 & 413 & 299 & 216 \\
\hline
\end{tabular}

Notes: Robust standard errors in parentheses.

Significance: $* \mathrm{p}<0.1 ; * * \mathrm{p}<0.05 ; * * * \mathrm{p}<0.01$.

Optimal bandwidths in bold.

Table D3. Impact on intakes from the afternoon snack for children taking both the morning and afternoon snack, all outcomes and all bandwidths.

\begin{tabular}{lrrrr}
\hline & \multicolumn{4}{c}{ Bandwidth } \\
Outcome & \multicolumn{1}{c}{$6-18$} & \multicolumn{1}{c}{717} & \multicolumn{1}{c}{8} & \multicolumn{1}{c}{$9-15$} \\
\hline Energy intake (Kcal) & 67.035 & 38.908 & 19.725 & $\mathbf{1 2 . 4 9 5}$ \\
& $(61.395)$ & $(66.630)$ & $(75.553)$ & $\mathbf{( 9 0 . 8 8 8 )}$ \\
Sugar intake $(\mathrm{g})$ & 0.323 & $\mathbf{- 1 . 2 4 5}$ & -1.454 & -3.483 \\
& $(5.269)$ & $\mathbf{( 5 . 9 2 5 )}$ & $(7.000)$ & $(8.371)$ \\
Fat intake (g) & 4.011 & 2.763 & 1.707 & $\mathbf{1 . 5 8 7}$ \\
& $(2.911)$ & $(3.134)$ & $(3.498)$ & $\mathbf{( 4 . 2 7 8 )}$ \\
Saturated fat intake $(\mathrm{g})$ & 1.075 & 0.344 & -0.752 & $\mathbf{- 0 . 1 0 5}$ \\
& $(1.528)$ & $(1.666)$ & $(1.777)$ & $\mathbf{( 2 . 1 8 5})$ \\
Snack frequency & -0.045 & -0.080 & $-0.158^{*}$ & $\mathbf{- 0 . 1 3 5}$ \\
& $(0.075)$ & $(0.083)$ & $(0.095)$ & $\mathbf{( 0 . 1 2 0})$ \\
$\mathrm{N}$ & 461 & 392 & 282 & 204 \\
\hline
\end{tabular}

Notes: Robust standard errors in parentheses.

Significance: $* \mathrm{p}<0.1$; ** $\mathrm{p}<0.05$; *** $\mathrm{p}<0.01$.

Optimal bandwidths in bold. 
Table D4. Impact on daily intakes for children taking both the morning snack and the afternoon snack, all outcomes and all bandwidths.

\begin{tabular}{lrrrr}
\hline & \multicolumn{4}{c}{ Bandwidth } \\
Outcome & \multicolumn{1}{c}{$6-18$} & \multicolumn{1}{c}{$7-17$} & \multicolumn{1}{c}{$8-16$} & \multicolumn{1}{c}{$9-15$} \\
\hline Energy intake (Kcal) & -49.871 & $\mathbf{- 3 2 . 5 8 0}$ & -140.715 & -273.527 \\
& $(157.849)$ & $\mathbf{( 1 7 2 . 0 4 3 )}$ & $(188.708)$ & $(234.175)$ \\
Sugar intake $(\mathrm{g})$ & 6.271 & $\mathbf{7 . 4 2 6}$ & 5.395 & 0.228 \\
& $(11.026)$ & $\mathbf{( 1 2 . 5 6 0 )}$ & $(15.661)$ & $(16.464)$ \\
Fat intake $(\mathrm{g})$ & 1.610 & 2.878 & $\mathbf{- 3 . 6 6 3}$ & -4.560 \\
& $(7.078)$ & $(7.711)$ & $\mathbf{( 8 . 7 0 8})$ & $(10.187)$ \\
Saturated fat intake $(\mathrm{g})$ & 0.227 & 0.945 & $\mathbf{- 3 . 0 4 2}$ & -2.926 \\
& $(3.499)$ & $(3.832)$ & $\mathbf{( 4 . 2 5 5 )}$ & $(5.032)$ \\
$\mathrm{N}$ & 461 & 392 & 282 & 204 \\
\hline
\end{tabular}

Notes: Robust standard errors in parentheses.

Significance: $* \mathrm{p}<0.1$; ** $\mathrm{p}<0.05$; *** $\mathrm{p}<0.01$.

Optimal bandwidths in bold.

Table D5. Impact on intakes from all meals except the snacks (morning and afternoon), for children taking both the morning and the afternoon snack, all outcomes and all bandwidths.

\begin{tabular}{lrrrr}
\hline \multirow{2}{*}{ Outcome } & \multicolumn{4}{c}{ Bandwidth } \\
\hline Energy intake (Kcal) & \multicolumn{1}{c}{-18} & \multicolumn{1}{c}{$7-17$} & \multicolumn{1}{c}{$8-16$} & \multicolumn{1}{c}{$9-15$} \\
& -98.526 & $\mathbf{- 8 1 . 2 7 9}$ & -178.535 & -284.630 \\
Sugar intake (g) & $(138.012)$ & $\mathbf{( 1 5 1 . 8 3 2})$ & $(163.669)$ & $(207.737)$ \\
& 9.517 & $\mathbf{1 2 . 8 6 3}$ & 10.046 & 4.184 \\
Fat intake (g) & $(8.408)$ & $\mathbf{( 9 . 5 6 3 )}$ & $(11.479)$ & $(12.497)$ \\
& -1.907 & $\mathbf{- 0 . 9 7 1}$ & -6.718 & -5.865 \\
Saturated fat intake $(\mathrm{g})$ & $(6.138)$ & $\mathbf{( 6 . 7 4 9 )}$ & $(7.718)$ & $(9.085)$ \\
& -0.736 & $\mathbf{- 0 . 0 9 6}$ & -3.092 & -2.620 \\
$\mathrm{~N}$ & $(2.911)$ & $\mathbf{( 3 . 2 0 5})$ & $(3.680)$ & $(4.446)$ \\
\hline
\end{tabular}

Notes: Robust standard errors in parentheses.

Significance: $* \mathrm{p}<0.1$; ** $\mathrm{p}<0.05$; $* * * \mathrm{p}<0.01$.

Optimal bandwidths in bold. 
Table D6. Impact on intakes from the afternoon snack for children taking the afternoon snack only, all outcomes and all bandwidths.

\begin{tabular}{lrrrr}
\hline & \multicolumn{4}{c}{ Bandwidth } \\
Outcome & \multicolumn{1}{c}{$6-18$} & \multicolumn{1}{c}{$7-17$} & \multicolumn{1}{c}{$8-16$} & \multicolumn{1}{c}{$9-15$} \\
\hline Energy intake (Kcal) & -39.800 & $\mathbf{- 2 1 . 7 6 6}$ & -18.135 & -44.939 \\
& $(39.502)$ & $\mathbf{( 4 2 . 2 9 7 )}$ & $(45.260)$ & $(51.087)$ \\
Sugar intake $(\mathrm{g})$ & $-11.568^{* * *}$ & $\mathbf{- 8 . 0 8 1} *$ & $-7.921^{*}$ & -7.351 \\
& $(3.876)$ & $\mathbf{( 4 . 2 4 3 )}$ & $(4.612)$ & $(5.637)$ \\
Fat intake (g) & -1.408 & $\mathbf{- 7 . 9 6 6 * *}$ & $-10.691^{* *}$ & $-13.865^{* *}$ \\
& $(1.781)$ & $\mathbf{( 3 . 7 3 7 )}$ & $(4.885)$ & $(6.887)$ \\
Saturated fat intake $(\mathrm{g})$ & -0.659 & $-4.266^{* *}$ & $-5.823^{* *}$ & $\mathbf{- 7 . 9 6 6 * *}$ \\
& $(0.913)$ & $(2.019)$ & $(2.661)$ & $\mathbf{( 3 . 8 1 9 )}$ \\
Snack frequency & 0.007 & 0.041 & 0.021 & $\mathbf{0 . 0 1 0}$ \\
& $(0.062)$ & $(0.067)$ & $(0.072)$ & $\mathbf{( 0 . 0 8 2})$ \\
N & 834 & $\mathbf{7 6 9}$ & 670 & 554 \\
\hline Notes: Robust standard errors in parentheses. & & &
\end{tabular}

Significance: $* \mathrm{p}<0.1 ; * * \mathrm{p}<0.05 ; * * * \mathrm{p}<0.01$.

Optimal bandwidths in bold.

Table D7. Impact on daily intakes for children taking the afternoon snack only, all outcomes and all bandwidths.

\begin{tabular}{|c|c|c|c|c|}
\hline \multirow[b]{2}{*}{ Outcome } & \multicolumn{4}{|c|}{ Bandwidth } \\
\hline & $6-18$ & $7-17$ & $8-16$ & $9-15$ \\
\hline \multirow[t]{2}{*}{ Energy intake (Kcal) } & -105.310 & -108.386 & -120.391 & -162.093 \\
\hline & (119.130) & (131.596) & $(146.256)$ & (166.143) \\
\hline \multirow[t]{2}{*}{ Sugar intake (g) } & -5.148 & -15.145 & -12.607 & -12.848 \\
\hline & $(10.960)$ & (10.034) & (11.000) & (12.253) \\
\hline \multirow[t]{2}{*}{ Fat intake $(\mathrm{g})$} & -4.633 & -4.019 & -2.406 & -3.108 \\
\hline & (5.376) & (5.942) & $(6.516)$ & (7.364) \\
\hline \multirow[t]{2}{*}{ Saturated fat intake $(\mathrm{g})$} & -1.823 & -1.741 & -1.465 & -2.631 \\
\hline & $(2.517)$ & $(2.760)$ & $(3.058)$ & (3.393) \\
\hline $\mathrm{N}$ & 804 & 742 & 647 & 536 \\
\hline
\end{tabular}

Significance: $* \mathrm{p}<0.1 ; * * \mathrm{p}<0.05 ; * * * \mathrm{p}<0.01$.

Optimal bandwidths in bold. 
Table D8. Impact on intakes from all meals except the afternoon snack, for children taking the afternoon snack only, all outcomes and all bandwidths.

\begin{tabular}{lrrrr}
\hline & \multicolumn{4}{c}{ Bandwidth } \\
Outcome & \multicolumn{1}{c}{$6-18$} & \multicolumn{1}{c}{$7-17$} & \multicolumn{1}{c}{$8-16$} & \multicolumn{1}{c}{$9-15$} \\
\hline Energy intake (Kcal) & -47.543 & $\mathbf{- 6 7 . 9 2 2}$ & -77.074 & -93.554 \\
& $(102.581)$ & $\mathbf{( 1 1 2 . 3 4 5 )}$ & $(124.161)$ & $(142.835)$ \\
Sugar intake $(\mathrm{g})$ & 4.518 & -4.029 & -2.397 & $\mathbf{- 3 . 2 3 3}$ \\
& $(8.913)$ & $(7.900)$ & $(8.595)$ & $\mathbf{( 9 . 1 0 8 )}$ \\
Fat intake (g) & -2.989 & -3.036 & $\mathbf{- 0 . 8 0 9}$ & -0.545 \\
& $(4.892)$ & $(5.363)$ & $\mathbf{( 5 . 8 4 1 )}$ & $(6.716)$ \\
Saturated fat intake $(\mathrm{g})$ & -0.974 & -1.277 & -0.705 & $\mathbf{- 1 . 4 1 6}$ \\
& $(2.273)$ & $(2.468)$ & $(2.741)$ & $\mathbf{( 3 . 1 0 0 )}$ \\
$\mathrm{N}$ & 804 & 742 & 647 & 536 \\
\hline
\end{tabular}

Notes: Robust standard errors in parentheses.

Significance: $* \mathrm{p}<0.1 ; * * \mathrm{p}<0.05 ; * * * \mathrm{p}<0.01$.

Optimal bandwidths in bold.

\footnotetext{
${ }^{1}$ See, for example, the Point/Counterpoint discussion in the Journal of Policy Analysis and Management, Vol. 30(2), Chaloupka et al. (2011), and Fletcher et al. (2011).

${ }^{2}$ Loi n. 2004-806, 9 August 2004.

${ }^{3}$ According to the 2006/2007 French nutrition survey only 1.4 percent of children aged 3 to 17 did not take any breakfast during the school week.

${ }^{4}$ Avis de l'Agence française de sécurité sanitaire des aliments relatif à la collation matinale à l'école, AFFSA note of 23 January 2004.

${ }^{5}$ Nutrition à l'École, Ministère de l'Éducation nationale, February 2009, page 10. Retrieved June 28, 2016, from http://media.eduscol.education.fr/file/Action_sanitaire et sociale/57/3/dossier_national_nutrition_114573.pdf.

${ }^{6}$ According to the definition followed by the INCA surveys, sugars include all monosaccharides and disaccharides naturally occurring or added to foods.

${ }^{7}$ Information on the school level attended by children is only provided in the INCA2 survey.

${ }^{8}$ For a recent methodological guide on the application of RD designs to the evaluation of public policies readers may refer to Cattaneo et al. (2017).

${ }^{9}$ According to OECD data in 200914.5 percent of 15 -year-old students reported that they had repeated a grade at least once at the primary education level (Ikeda et al., 2013).

${ }^{10}$ The proportion of misclassified students is almost identical, but slightly lower at 12, 5.5 percent versus 5.6 percent with a cut-off at 11 in the INCA2 survey.

${ }^{11}$ The school level is stated explicitly in the INCA2 survey.

${ }^{12}$ Although it is not necessary to adopt a logit or probit specification (Lee \& Lemieux, 2010), we compared the OLS results with those from a logit model, and we found no detectable difference. First stage estimates with both methods are provided in the Appendix, together with the second stage estimates using predictions from a logit model. All appendices are available at the end of this article as it appears in JPAM online. Go to the publisher's website and use the search engine to locate the article at http://onlinelibrary.wiley.com.

${ }^{13}$ Full estimation results are reported in the Appendix. All appendices are available at the end of this article as it appears in JPAM online. Go to the publisher's website and use the search engine to locate the article at http://onlinelibrary.wiley.com.

${ }^{14}$ The impact found on saturated fats is not particularly robust or indicative, as it is significant at the 10 percent
} 
level in the optimal bandwidth only, but non-significant in all other potential bandwidths (see Appendix). All appendices are available at the end of this article as it appears in JPAM online. Go to the publisher's website and use the search engine to locate the article at http://onlinelibrary.wiley.com.

${ }^{15}$ For the sake of brevity we only show results on sugar intakes on the optimal bandwidth, but the complete tables are available in the Appendix. All appendices are available at the end of this article as it appears in JPAM online. Go to the publisher's website and use the search engine to locate the article at http://onlinelibrary.wiley.com.

${ }^{16}$ All appendices are available at the end of this article as it appears in JPAM online. Go to the publisher's website and use the search engine to locate the article at http://onlinelibrary.wiley.com.

${ }^{17}$ All appendices are available at the end of this article as it appears in JPAM online. Go to the publisher's website and use the search engine to locate the article at http://onlinelibrary.wiley.com.

${ }^{18}$ All appendices are available at the end of this article as it appears in JPAM online. Go to the publisher's website and use the search engine to locate the article at http://onlinelibrary.wiley.com.

${ }^{19}$ All appendices are available at the end of this article as it appears in JPAM online. Go to the publisher's website and use the search engine to locate the article at http://onlinelibrary.wiley.com. 